
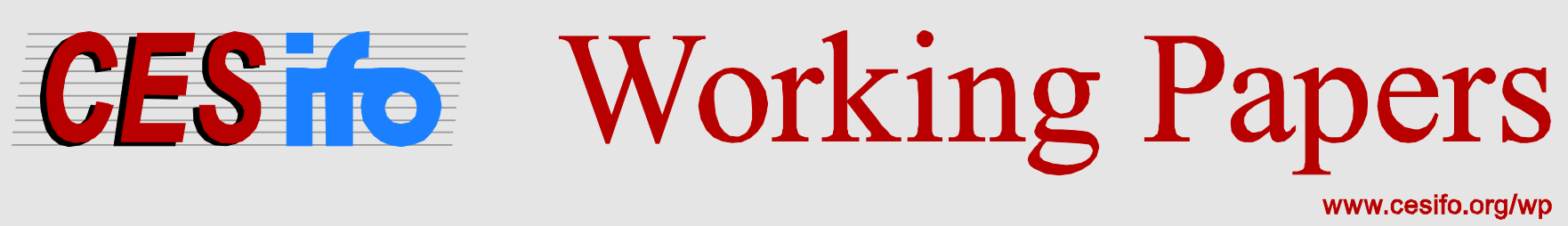

\title{
Beauty Premium and Marriage Premium in Search Equilibrium: Theory and Empirical Test
}

\author{
Roberto Bonilla \\ Francis Kiraly \\ John Wildman
}

CESIFO WORKING PAPER NO. 5242

CATEGORY 4: LABOUR MARKETS

ORIGINAL VERSION: MARCH 2015

THIS VERSION: JUNE 2017
An electronic version of the paper may be downloaded
- from the SSRN website:
- from the RePEc website:
- from the CESifo website:
wWw.SSRN.com
www.RePEc.org
www.CESifo-group.org/wp




\title{
Beauty Premium and Marriage Premium in Search Equilibrium: Theory and Empirical Test
}

\begin{abstract}
We propose a theoretical explanation for the so-called "beauty premium". Our approach relies entirely on search frictions and the fact that physical appearance plays an important role in attracting a marriage partner. We analyse the interaction between frictional labour and marriage markets, making use of what we label constrained job search. The optimal strategy entails different reservation wages for different men, and we establish the existence of a search equilibrium characterised by beauty premium and/or marriage premium. Predicted profiles of premia allow for potential falsification tests and point to relevant empirical evidence in support of our theory.
\end{abstract}

JEL-Code: D830, J120, J310.

Keywords: search, frictional labour market, frictional marriage market, beauty premium, marriage premium.

\author{
Roberto Bonilla* \\ Newcastle University \\ 5 Barrack Road \\ United Kingdom - NE1 4SE Newcastle Upon Tyne \\ roberto.bonilla@ncl.ac.uk
}

Francis Z. Kiraly

Newcastle University

5 Barrack Road

UK - NE1 4SE Newcastle Upon Tyne

francis.kiraly@ncl.ac.uk

\author{
John Wildman \\ Newcastle University \\ 5 Barrack Road \\ UK - NE1 4SE Newcastle Upon Tyne \\ john.wildman@ncl.ac.uk
}

*corresponding author

We would like thank the Editor (Guido Menzio), and two anonymous referees for insightful suggestions that helped us improve the paper. We are also grateful to Melvyn Coles, Peter Dolton, Daniel Hamermesh, Adrian Masters, Alberto Trejos and Mich Tvede. 


\section{Introduction}

There is widespread evidence that labour market outcomes are influenced by more than just productivity. Anthropometric characteristics such as beauty, height and - to some extent - weight also appear to have an effect on employment and wages. In particular, individuals perceived as having attractive physical attributes tend to earn higher wages. In the literature, this earnings gap is referred to as the "beauty premium", and has been the subject of extensive empirical research.

We offer an explanation for the existence of male beauty premium as an equilibrium outcome. Our theoretical model incorporates two crucial features of labour and marriage markets. First, both markets are characterised by search frictions: it takes time, effort and luck to find a suitable job or marital partner. Second, matching in the marriage market seems to involve multi-dimensional preferences which reflect an implicit trade-off between anthropometric and socio-economic characteristics.

The key message of our paper is that labour market decisions and outcomes (including various types of wage premia) may be influenced by expectations and behaviour in the marriage market, and vice versa.

To capture this inter-dependence, we construct a simple equilibrium search model where the two frictional markets are inter-linked. ${ }^{1}$ Single men are heterogeneous in terms of their physical appearance: in the eyes of all women, some men are more attractive than others. We consider a two-sided search scenario, where men and women look for each other, and unemployed men search for jobs knowing that earnings, together with physical attributes determine whether or not they can form marriage partnerships.

In our model, physical appearance does not affect men's options in the as well as participants at the 2014 EALE Conference (Ljubljana) and the 2015 Search and Matching (SaM) Annual Meeting (Aix-en-Provence) for many useful comments. R. Bonilla also thanks CESifo and Universidad de Oviedo for logistical support.

${ }^{1}$ The literature on inter-linked frictional markets is sparse. For two very interesting recent papers, see Kaplan and Menzio (2016) and Rupert and Wasmer (2012). 
labour market. Crucially however, it does affect their decisions in that market, as their marriage prospects are influenced by both looks and wages. We call this type of decision problem constrained search, and analyse it in detail.

If women regard physical characteristics and wages as substitutes and rank men in the same way, we show that there exists an equilibrium in which less attractive men find it optimal to accept jobs that pay lower wages than those of their more attractive rivals. The trade-off is straightforward and it is due to the frictional nature of the labour market: although a less attractive man needs a relatively high wage in order to be accepted by a woman, such a well-paid job may be too difficult to find, so he settles for a lower wage. As a consequence, more attractive men (single or married) will earn, on average, higher wages than less attractive (single or married) men.

Our approach incorporates some aspects of the marriage market whose importance was stressed by Chiappori et al.(2012) in the context of assortative matching. They argue that the standard marriage matching framework is too narrow, in the sense that it overlooks the role played by uncertainty and it restricts attention to one-dimensional preferences. That is, it tends to play down the role of search frictions and, in the main, it ignores preferences towards multiple characteristics and the potential trade-offs this implies. ${ }^{2}$ We incorporate the random nature of matching and also consider preferences over multi-dimensional (anthropometric and socio-economic) characteristics. Indeed, our results are driven entirely by the very existence of such search frictions and the perceived trade-off between physical attributes and wages. The only other papers we are aware of that consider marital matching with multiple attributes in a search equilibrium framework are Coles and Francesconi (2011 and 2013), with fascinating insights into some possible effects of equal opportunities for women.

\footnotetext{
${ }^{2}$ Chiappori et al.(2012) consider marital matching along multi-dimensional character-
} istics and reduce it to a matching problem with preferences captured by a one-dimensional index. Using PSID data on married couples, they also find an interesting trade-off between anthropometric and socio-economic factors affecting marital outcomes: men compensate 1.3 additional units of BMI with a $1 \%$ increase in wages. 
Interestingly, the strategies which give rise to the beauty premium can also account for the so-called "marriage premium": the puzzling empirical fact that on average, married men earn higher wages than their single counterparts. ${ }^{3}$ We are the first to establish a theoretical link between the two types of premia as equilibrium outcomes.

The potential market equilibria, each characterised by very specific patterns of beauty premium and marriage premium, allow for an extensive empirical test of our theoretical predictions. Using British data, we estimate the two types of wage differentials across male workers who differ in terms of anthropometric characteristics. Following the literature, we use height and weight as proxies for physical attractiveness, and the estimates seem to be in line with the theory. Our empirical analysis constitutes the very first attempt at finding support for the search theoretic approach to beauty premium and marriage premium. ${ }^{4}$

Hamermesh (2011) offers a stimulating survey of the literature on beauty premium. Hamermesh and Biddle (1994) find that individuals with belowaverage attractiveness earn $9 \%$ less than the "average-looking" ones, while the wage of individuals with above-average looks is $5 \%$ higher. These results are obtained after controlling for educational attainment and experience. Persico et al. (2004) attempt to quantify the so-called height premium and observe that increasing height at age 16 by one inch increases adult wages by $2.6 \%$, on average. In two fairly recent studies using UK data, Case and Paxson (2008) and Case at al.(2009) find that the height premium remains significant after controlling for education and for sorting into higher status jobs. The effect of weight on labour market outcomes seems to be less clear.

\footnotetext{
${ }^{3}$ Numerous studies report that after controlling for education and other characteristics, the male marriage premium is consistently around $10 \%$ or above, while such marital wage differentials are considerably smaller for women, and their sign varies. For excellent surveys of the empirical literature on the male marriage wage premium, see Daniel (1995) or Grossbard-Shechtman and Neuman (2003).

${ }^{4}$ In their survey chapter, Ponthieux and Meurs (2014) stress the need for such empirical studies aimed at testing the search theoretical approach to various wage inequalities.
} 
Garcia and Quintana-Domeque (2007), Cawley (2004) and Han et al.(2009) find a wage penalty coupled with reduced employment probability for the obese. In contrast, Hamermesh and Biddle (1994), Sargent and Blanchflower (1994) and Morris (2006) argue that weight has no effect on male earnings.

Physical attributes (beauty, weight and height) are known to play an important role in the marriage market. Extensive empirical studies from sociology, anthropology, psychology and other fields confirm this. Following the ground-breaking work of Becker (1991) there is also an extensive economics literature that investigates assortative mating. Some studies, such as Choo and Siow (2006) and Weiss and Willis (1997) focus on matching based on age, earnings and education. Others consider the effect of various anthropometric characteristics on marital outcomes. For height, Oreffice and Quintana-Domeque (2010) find that shorter men are more likely to be matched with less educated and heavier partners, while Ponzo and Scoppa (2015) conclude that taller males tend to marry more educated women. Manfredini et al.(2013) observe a negative selection of short men on marriage, while Herpin (2005) finds that short men are less likely to be married or live in a permanent relationship than their taller counterparts. For weight, Oreffice and Quintana-Domeque (2010) find that heavier husbands are matched with shorter wives, while Silventoinen et al.(2003) observe assortative matching along weight, as well as height. Finally, Averett et al.(2008) note that spouses tend to pay less attention to their body-mass index (BMI) once they get married.

The present paper complements the existing literature in two other important ways. First, we ignore the wage policies of firms, and hence issues related to possible discrimination based on looks. Second, productivity heterogeneity plays no role whatsoever in establishing our results. All this is in stark contrast with existing explanations of beauty premium and marriage premium, which either implicitly assume discrimination in the labour market, or rely on some sort of productivity differences.

Indeed, most of the current literature on beauty premium is based on the idea that some physical traits might affect job performance in ways that are not as easily measured as other factors (such as human capital or work experience). One argument is that physical attractiveness may affect a person's self-esteem or communication skills, and hence their productivity. Cawley 
(2004) finds that productivity is negatively correlated with weight, possibly because of factors such as health or confidence. Persico et al.(2004) observe that height increases the probability that teens participate in social activities, and in turn these activities help them acquire productivity-enhancing skills. However, Hamermesh and Biddle (1994) find that the beauty premium exists even outside of jobs that involve frequent inter-personal contact and communication.

In turn, the standard (non search theoretic) explanations of marriage premium tend to rely on some sort of male productivity heterogeneity. According to the so-called selection theory, some unobservable traits of men which are valued in the marriage market are correlated with productivity. However, the empirical evidence on this is quite weak - for example, Chun and Lee (2001) argue that the selection effect is minimal. Alternatively, the household specialisation approach posits that marriage increases a man's productivity. Although Korenman and Neumark (1991) provide some limited empirical support for this hypothesis, Loh (1996) finds that men whose wives also work earn a larger premium, while Hersch and Stratton (2000) conclude that the marriage premium is not due to household specialisation even if one does not use wives' employment status as a proxy for specialisation. Blackburn and Korenman (1994) assess the relative merits of the two theories mentioned above and argue that the evidence is mixed, so neither selection nor specialisation seem to be sufficient or satisfactory explanations for the existence of the male marriage wage gap.

In this context, the only theoretical work we are aware of that offers an alternative explanation for the existence of marriage premium is Bonilla and Kiraly (2013), who show that the marital earnings gap can arise simply as a result of search frictions.

Next, we set up our theoretical framework. In Section 3 we analyse the optimal strategies of men and women, with focus on the constrained sequential job search problem facing unemployed males. In Section 4 we present the search equilibrium configurations, with emphasis on those characterised by beauty premium. We also establish the link between beauty premium and marriage premium. In Section 5 we carry out an empirical falsification test of the model, and offer additional evidence in support of our theory. The final section offers a summary and discussion of the main results. 


\section{The model}

The economy consists of a continuum of women and men, all risk neutral. Time is continuous and all agents discount the future at rate $r$. Only steady state equilibria are considered.

Men enter the economy unemployed and single. In the labour market, they all face a range of posted wages which are distributed according to the exogenous cumulative distribution function $F(w)$ with support $[\underline{w}, \bar{w}]$. Men use costless random sequential search to locate firms, and contact occurs at rate $\lambda_{0}$. An employed man has flow wage payoff $w$. There is no on-the-job search, so a man's wage remains constant throughout his working life.

In the marriage market, a man is viewed by all women as either attractive $(H)$ or less attractive $(L)$. That is, men are heterogeneous (with $i=H, L$ denoting type) in terms of their physical appearance. Let $u_{i}$ denote the steady state measure of single unemployed men of type $i$. One can think of appearance as a composite quality which captures anthropometric traits such as beauty, height and weight - characteristics that are all known to be important in marital matching. Single men look for potential partners. A married man earning wage $w$ enjoys flow payoff $w+y$, where $y>0$ captures the non-material utility of marriage. Assume there is no possibility of divorce. In the marriage market, meetings occur according to a quadratic matching function, where the number of meetings is proportional to the product of the measure of searchers on each side of the market. This (see Mortensen, 1982) gives rise to a Poisson meeting technology with an arrival rate that is a linear function of the relevant measure of participants on the opposite side of the market. For men, we denote this arrival rate by $\lambda_{m}$.

Let $n$ denote the measure of single women. They do not look for jobs, and let $x$ denote the exogenous flow payoff of a single woman. ${ }^{5}$ Women use costless random sequential search to locate single eligible (marriageable) males. A married woman's flow payoff is equal to her partner's wage $w$ plus a fixed flow utility $z_{i}$, where $z_{H}>z_{L}$. The payoff $z_{i}$ captures the non-monetary utility a woman gets from marrying a type $i$ man. ${ }^{6}$ This is a crucial ingredient in our model and it captures two important considerations. First, it allows some participants in the marriage matching process (in this case,

\footnotetext{
${ }^{5}$ Alternatively, $x$ could be endogenous in a labour market where women are active.

${ }^{6}$ Normalising $z_{L}$ to zero is without loss of generality, and we will make use of this later.
} 
women) to have preferences about multi-dimensional features of potential marital partners. Second, it reflects the perceived trade-off between anthropometric characteristics and socio-economic status: here, all women regard a man's wage and his looks as perfect substitutes. Physical appearance, together with earnings, determine whether or not a single man is accepted for marriage. Possible asymmetries in the way women and men value the benefits of marriage are captured by the relationship between parameters $x$, $z_{i}$ and $y$. Upon marriage a woman gives up $x$, so we assume that $x<\bar{w}$ to ensure that a marital partnership does have a positive potential surplus. Let $\lambda_{w}^{i}$ and $\lambda_{w}^{u}$ be the parameters of the Poisson process and hence the rate at which a woman meets an employed man (of type $i$ ) or an unemployed, respectively.

Marriages are "for life". Nevertheless, couples and singles alike leave the economy at an exogenous rate $\delta$. Every time an unemployed single man of type $i$ accepts a job, gets married or leaves the economy, he is replaced by another type $i$ unemployed single man. Hence, $u_{i}$ can be treated as exogenous. Furthermore, we assume that a new single woman comes into the market every time a single woman gets married or exits the economy, so $n$ can also be regarded as exogenous.

Denote by $\lambda$ the parameter which measures the efficiency of the meeting process. Let $N_{i}$ denote the measure of marriageable employed single men of type $i$. Then, from a single man's point of view, the average instantaneous rate at which meetings occur is $\lambda_{m}=\frac{\lambda\left(N_{H}+N_{L}\right) n}{\left(N_{H}+N_{L}\right)}=\lambda n$. Similarly, from the point of view of single women, the rate at which meetings with unemployed men occur is given by $\lambda_{w}^{u}=\frac{\lambda\left(u_{H}+u_{L}\right) n}{n}$, while the corresponding rate of meeting employed men of type $i$ is $\lambda_{w}^{i}=\frac{\lambda\left(N_{H}+N_{L}\right) n}{n} \frac{N_{i}}{\left(N_{H}+N_{L}\right)}=\lambda N_{i}$. The steady state measure $N_{i}$ is of course endogenous, and therefore so is $\lambda_{w}^{i}$, as well as steady state measures of unmarriageable men (bachelors, denoted by $B_{i}$ ) and of married men $\left(M_{i}\right)$.

We define the beauty premium $(B P)$ as the difference between the average wage of type $H$ men (married or single) and the average wage of type $L$ men (married or single). Similarly, we define the marriage premium $(M P)$ among men of type $i$ as the difference between the average wage of type $i$ married men and that of type $i$ single men. Throughout, superscripts $S$ and $M$ stand for "single" and "married". 


\section{Optimal search}

Given sequential search and the fact that utilities are increasing in wages, we show that both men and women use optimal strategies characterised by the reservation property. For men, this means a reservation wage $R_{i}$, or more precisely, a reservation wage function $R_{i}\left(T_{i}\right)$, where $T_{i}$ is the reservation match of women. In turn, the latter is essentially a reservation wage strategy $T_{i}\left(z_{i}\right)$, simply because income and looks are regarded as perfect substitutes.

Throughout, we denote by $\Delta>0$ an arbitrarily small time period, so the common discount factor is $\frac{1}{1+r \Delta}$.

\subsection{Men}

All men, regardless of type, face similar job prospects: they all face the same wage distribution $F($.$) , and the other relevant structural parameters \left(\lambda_{0}, r\right.$ and $\delta$ ) are also common. Crucially however, men's prospects in the marriage market do differ across types, and will also depend on employment status. Because of this, we first examine the case when unemployed men are not accepted by women.

\subsubsection{Unemployed men and marriage}

Consider a married and employed man of type $i$. Without the possibility of either on-the-job search or divorce, and conditional on survival, his payoff from working during the period $\Delta$ is given by:

$$
V_{i}^{M}(w)=\frac{1}{1+r \Delta}\left[w \Delta+y \Delta+(1-\delta \Delta) V_{i}^{M}(w)\right] .
$$

During the current period, this man earns utility from wage and marriage and, with probability $(1-\delta \Delta)$, his value will be the same in the next period.

For $\Delta \rightarrow 0$, we obtain the discounted expected lifetime utility:

$$
V_{i}^{M}(w)=\frac{w+y}{r+\delta}
$$


Although this value is clearly not type-dependent, in the interest of clarity we will continue to use these subscripts, even when we have type independence.

Given that a married unemployed man of type $i$ receives a wage offer $w$ and behaves optimally in each period, the relevant Bellman equation in his case is:

$$
v_{i}^{M}(w)=\max \left\{V_{i}^{M}(w), J_{i}^{M}\right\},
$$

where $J_{i}^{M}$ captures a married jobless man's value from continued job search. We have:

$$
J_{i}^{M}=\frac{1}{1+r \Delta}\left[y \Delta+(1-\delta \Delta)\left(1-\lambda_{0} \Delta\right) J_{i}^{M}+(1-\delta \Delta) \lambda_{0} \Delta \int_{\underline{w}}^{\bar{w}} v_{i}^{M}(w) d F(w)+o(\Delta)\right] .
$$

In the current period, a married unemployed man enjoys the flow utility $y$ from marriage. If he survives this period but does not encounter a job offer, he remains on his current value $J_{i}^{M}$. Alternatively, if he does obtain an offer $w$, his payoff next period will be the expected continuation value $v_{i}^{M}(w)$. The $o(\Delta)$ term captures the Poisson approximation over the small time interval $\Delta$ and has the property that $o(\Delta) / \Delta \rightarrow 0$ as $\Delta \rightarrow 0$ (reflecting the fact that the probability of multiple events occurring within a single short period is negligible).

Rearranging the above, dividing by $\Delta$ and taking the limit as $\Delta \rightarrow 0$ yields the continuous time Bellman equation:

$$
J_{i}^{M}=\frac{1}{r+\delta+\lambda_{0}}\left[y+\lambda_{0} \int_{\underline{w}}^{\bar{w}} v_{i}^{M}(w) d F(w)\right] .
$$

As before, the left-hand side describes the value of being married and unemployed. The right-hand side describes the expected discounted return. Here, $y$ is the instantaneous payoff from marriage and the second term in the brackets captures the expected utility of any change in the value of this man's state, which in this case is the probability that he receives a job offer $\left(\lambda_{0}\right)$, times the expected continuation value associated with the offer $w$, noting that the offer can be rejected. 
Clearly, $J_{i}^{M}$ is independent of any current wage offer. Given that $V_{i}^{M}(w)$ is continuous and increasing in the accepted offer $w$, the optimal strategy has the reservation property. Let $R_{i}^{M}$ denote the reservation wage. Manipulation of the above leads to:

$$
(r+\delta) J_{i}^{M}=y+\lambda_{0} \int_{R_{i}^{M}}^{\bar{w}}\left[V_{i}^{M}-J_{i}^{M}\right] d F(w) .
$$

The reservation wage $R_{i}^{M}$ solves the standard equation:

$$
J_{i}^{M}=V_{i}^{M}\left(R_{i}^{M}\right)=\frac{R_{i}^{M}+y}{r+\delta} .
$$

Consequently, we get:

$$
R_{i}^{M}=\frac{\lambda_{0}}{r+\delta} \int_{R_{i}^{M}}^{\bar{w}}\left[w-R_{i}^{M}\right] d F(w) .
$$

Alternatively, integrating by parts, we obtain:

$$
R_{i}^{M}=\frac{\lambda_{0}}{r+\delta} \int_{R_{i}^{M}}^{\bar{w}}[1-F(w)] d w
$$

Since both types of men face exactly the same prospects in the labour market, we have $R_{H}^{M}=R_{L}^{M} \equiv \underline{R}$, where:

$$
\underline{R}=\frac{\lambda_{0}}{r+\delta} \int_{\underline{R}}^{\bar{w}}[1-F(w)] d w .
$$

Note that $\underline{R}$ is also the reservation wage in a standard sequential job search problem without a marriage market. We will show later that $\underline{R}$ is in fact the lowest reservation wage in our story.

Consider now the situation of a woman who is married to a type $i$ unemployed man (hence the subscript $U_{i}$ ). Her value function $W_{U_{i}}^{M}$ is given by:

$$
\begin{gathered}
(1+r \Delta) W_{U_{i}}^{M}=z_{i} \Delta+(1-\delta \Delta)\left(1-\lambda_{0} \Delta\right) W_{U_{i}}^{M}+(1-\delta \Delta) \lambda_{0} \Delta F(\underline{R}) W_{U_{i}}^{M}+ \\
+(1-\delta \Delta) \lambda_{0} \Delta[1-F(\underline{R})] \int_{\underline{R}}^{\bar{w}} W_{i}^{M}(w) d F(w \mid w>\underline{R})+o(\Delta),
\end{gathered}
$$


where, $W_{i}^{M}(w)=\frac{w+z_{i}}{r+\delta}$ is the value of being married to a type $i$ man who earns a wage $w$ (given no on-the-job search or divorce).

During the current period, this woman benefits from the flow payoff $z_{i}$ from her marriage to a type $i$ unemployed. Conditional on survival, she remains on the value $W_{U_{i}}^{M}$ if her partner does not encounter a job offer, or if he does but chooses to reject that offer. Alternatively, if the man obtains a wage offer and accepts it, the woman's utility becomes the expected value of $W_{i}^{M}(w)$.

Suitably rearranging this, dividing by $\Delta$ and taking the limit as $\Delta \rightarrow 0$ leads to the flow Bellman equation:

$$
(r+\delta) W_{U_{i}}^{M}=z_{i}-\lambda_{0}[1-F(\underline{R})] W_{U_{i}}^{M}+\lambda_{0}[1-F(\underline{R})] \int_{\underline{R}}^{\bar{w}} W_{i}^{M}(w) d F(w \mid w>\underline{R}) .
$$

Moving all $W_{U_{i}}^{M}$ terms into the integral, we obtain:

$$
(r+\delta) W_{U_{i}}^{M}=z_{i}+\lambda_{0} \int_{\underline{R}}^{\bar{w}}\left[W_{i}^{M}(w)-W_{U_{i}}^{M}\right] d F(w) .
$$

For a woman, the flow value of being married to a type $i$ unemployed man is equal to the instantaneous marriage utility $z_{i}$ plus the expected utility from any increase in her value if the man encounters and accepts a job offer $w$.

If $T_{i}$ is a reservation match, then $W_{U_{i}}^{M}=\frac{T_{i}+z_{i}}{r+\delta}$. Substituting this, and making use of $W_{i}^{M}(w)$ above gives:

$$
(r+\delta) W_{U_{i}}^{M}=z_{i}+\frac{\lambda_{0}}{r+\delta} \int_{\underline{R}}^{\bar{w}}\left[w-T_{i}\right] d F(w) .
$$

Since $\frac{\lambda_{0}}{r+\delta} \int_{\underline{R}}^{\bar{w}}\left(w-T_{i}\right) d F(w)=\underline{R}$ for $T_{i}=\underline{R}$, we obtain:

$$
(r+\delta) W_{U_{i}}^{M}=z_{i}+T_{i}=z_{i}+\underline{R} .
$$

In contrast, for $\underline{R}<T_{i}$ we have:

$$
(r+\delta) W_{U_{i}}^{M}>z_{i}+\underline{R},
$$

and we are ready to state our first result:

Lemma 1 If $T_{i}>\underline{R}$, women reject marriage to a type $i$ unemployed man. 


\subsubsection{Constrained job search and the reservation wage function}

In the labour market, unemployed men are involved in what we call constrained search: they look for jobs knowing that the only way they can hope to get married is by earning a wage which is higher (or equal) to women's reservation match. With this in mind, a type $i$ unemployed man follows an optimal stopping strategy, and will have a reservation wage function $R_{i}\left(T_{i}\right)$.

We first consider the range $T_{i} \in(\underline{R}, \bar{w}]$. Unemployed men are not accepted for marriage, but employed men could in principle earn wages that make them acceptable for women.

Take a single unemployed man of type $i$ who has just received an offer $w$. This wage makes him either marriageable or not marriageable. Let $V_{i}^{S}(w)$ be the value of accepting such a job. Then, with $V_{i}^{M}(w)$ denoting the value of being married and working at wage $w$, we have:

For $w \geq T_{i}$

$V_{i}^{S}(w)=\frac{1}{1+r \Delta}\left[w \Delta+(1-\delta \Delta)(1-\lambda n \Delta) V_{i}^{S}(w)+(1-\delta \Delta) \lambda n \Delta V_{i}^{M}(w)+o(\Delta)\right]$.

For $w<T_{i}$,

$V_{i}^{S}(w)=\frac{1}{1+r \Delta}\left[w \Delta+(1-\delta \Delta)(1-\lambda n \Delta) V_{i}^{S}(w)+(1-\delta \Delta) \lambda n \Delta V_{i}^{S}(w)+o(\Delta)\right]$

If the wage $w$ accepted by the man is high enough so that he becomes marriageable, his value from employment is as follows. In the current period, this man obtains a flow utility from the wage $w$. If he survives into the next period but does not meet a woman, he remains on the current value $V_{i}^{S}$. However, if he does meet a woman, his payoff becomes $V_{i}^{M}(w)$.

Alternatively, if an unemployed man accepts a wage $w$ that is lower than what women demand, his value of employment remains unchanged, irrespective of whether he does or does not meet any women.

Suitably rearranging the above, dividing by $\Delta$ and taking limits as $\Delta \rightarrow 0$ yields the following expression:

$$
V_{i}^{S}(w)=\left\{\begin{array}{lll}
\frac{w}{r+\delta}+\frac{\lambda n}{(r+\delta+\lambda n)(r+\delta)} y & \text { if } & w \geq T_{i} \\
\frac{w}{r+\delta} & \text { if } & w<T_{i}
\end{array}\right\}
$$


Note that the value of accepting an offer $w$ is a piecewise linear function. It is increasing in wage $w$ and discontinuous at $w=T_{i}$.

Let $\bar{v}_{i}(w)$ be the expected value for a type $i$ unemployed who holds a current offer $w$ that confers marriageability, and let $\underline{v}_{i}(w)$ denote the value of holding a wage offer that precludes marriage.

This man has to decide whether to accept of reject such an offer. Let $J_{i}$ denote the value attached to continued job search by a type $i$ unemployed man, and note that for any current wage offer $w$, this value $J_{i}$ is independent of $w$.

The corresponding two Bellman equations are:

$$
\bar{v}_{i}(w)=\max \left\{V_{i}^{S}\left(w \mid w \geq T_{i}\right), J_{i}\right\}
$$

and

$$
\underline{v}_{i}(w)=\max \left\{V_{i}^{S}\left(w \mid w<T_{i}\right), J_{i}\right\}
$$

For $y>0$ we have $V_{i}^{S}\left(w \mid w \geq T_{i}\right)>V_{i}^{S}\left(w \mid w<T_{i}\right)$, and therefore $\bar{v}_{i} \geq \underline{v}_{i}$. The latter is with strict inequality if $V_{i}^{S}\left(w \mid w \geq T_{i}\right)>J_{i}$, which in turn is true for $T_{i}>\underline{R}$ (as will be shown in the proof of Proposition 1 below).

Regardless of the current wage offer $w$, and provided there is contact with an other firm, continued job search results in a new wage offer $w^{\prime}$. Given the distribution $F($.$) , the probability with which this w^{\prime}$ is higher or lower than the women's reservation match $T_{i}$ depends on $T_{i}$ itself.

Crucially, this means that $J_{i}$ is a convex combination of $\bar{v}_{i}(w)$ and $\underline{v}_{i}(w)$. To see this, note that $J_{i}$ is given by:

$$
\begin{gathered}
(1+r \Delta) J_{i}=(1-\delta \Delta)\left(1-\lambda_{0} \Delta\right) J_{i}+ \\
+(1-\delta \Delta) \lambda_{0} \Delta\left\{\left[1-F\left(T_{i}\right)\right] \int_{T_{i}}^{\bar{w}} \bar{v}_{i}\left(w^{\prime}\right) d\left[\frac{F\left(w^{\prime}\right)}{1-F\left(T_{i}\right)}\right]+F\left(T_{i}\right) \int_{\underline{w}}^{T_{i}} \underline{v}_{i}\left(w^{\prime}\right) d\left[\frac{F\left(w^{\prime}\right)}{F\left(T_{i}\right)}\right]\right\}+ \\
+o(\Delta) .
\end{gathered}
$$

Conditional on survival, the value of job search remains at $J_{i}$ if the unemployed man does not encounter a firm. If he does, with probability $1-F\left(T_{i}\right)$ 
the wage offer confers marriageability, and his payoff next period will be the expected continuation value $\bar{v}_{i}(w)$. Alternatively, and with probability $F\left(T_{i}\right)$, the wage offer precludes marriage, in which case his next period utility will be the expected continuation value $\underline{v}_{i}(w)$.

It is now clear that the value of job search $J_{i}$ is indeed independent of the current wage offer $w$, and it is a convex combination of the two conditional expected continuation values $\bar{v}_{i}$ and $\underline{v}_{i}$.

Rearranging, dividing by $\Delta$ and taking the limit as $\Delta \rightarrow 0$ we obtain the continuous time Bellman equation:

$$
J_{i}=\frac{\lambda_{0}}{r+\delta+\lambda_{0}}\left[\int_{T_{i}}^{\bar{w}} \bar{v}_{i}\left(w^{\prime}\right) d F\left(w^{\prime}\right)+\int_{\underline{w}}^{T_{i}} \underline{v}_{i}\left(w^{\prime}\right) d F\left(w^{\prime}\right)\right] .
$$

As before, the left-hand side describes the value of searching for a job, knowing that a potential wage offer either confers marriageability or precludes the prospect of marriage. The right-hand side describes the expected discounted return. The terms in the brackets capture the expected utility of any change in the value of an unemployed man's state. Here, this amounts to the probability that he receives a wage offer $\left(\lambda_{0}\right)$, times the expected continuation value associated with the offer $w^{\prime}$, noting that the offer can be accepted or rejected and, if accepted, it either allows for or precludes the subsequent possibility of marriage.

It is easy to see that for any $T_{i}<\bar{w}$, the continuation value $J_{i}$ is continuous. Furthermore, for $\bar{v}_{i}>\underline{v}_{i}$ the value $J_{i}$ is decreasing in $T_{i}$. On the other hand, for $T_{i} \geq \bar{w}$ we have $F\left(T_{i}\right)=1$ and $J_{i}$ is independent of $T_{i}$.

The following female reservation match will prove very useful.

Definition 1 Let $\widehat{T}_{i}$ be the $T_{i}$ for which $J_{i}\left(T_{i}\right)=\frac{w}{r+\delta}$ at $w=T_{i}$.

Making use of this $\widehat{T}_{i}$, Figure 1 plots $V_{i}^{S}(w)$ and $J_{i}\left(T_{i}\right)$. 
FIGURE 1 (please see at the end of the paper)

It is immediately apparent that with constrained sequential search, the above picture is quite different from the familiar diagram encountered in the standard theory of job search.

First, now there is a discontinuity in the value of accepting a job, at a wage $w=T_{i}$. As mentioned above, this makes $V_{i}^{S}$ a piecewise linear function that is piecewise continuous and increasing. The exact point at which the break occurs is of course determined by the value of $T_{i}$, moving to the right as $T_{i}$ increases.

Second, although the value of job search $J_{i}$ is independent of $w$, it is in fact a convex combination of two continuation values. Although independent of the current wage offer, $J_{i}$ is nonetheless a function of $T_{i}$. On the diagram, an increase in $T_{i}$ leads to a continuous downward shift in $J_{i}$.

Figure 1 shows that the optimal strategy has the reservation property, and clarifies how the reservation wage $R_{i}$ is determined for different values of $T_{i}$.

Panel $(b)$ depicts the case when $T_{i}=\widehat{T}_{i}$. For a wage $w<T_{i}\left(=\widehat{T}_{i}\right)$, we have $J_{i}>V_{i}^{S}\left(w \mid w<T_{i}\right)$, while for a wage $w \geq T_{i}\left(=\widehat{T}_{i}\right)$, we have $J_{i}<V_{i}^{S}\left(w \mid w \geq T_{i}\right)$. The reservation wage is therefore $R_{i}=\widehat{T}_{i}$.

Panel (a) illustrates the case with $T_{i} \in\left(\underline{R}, \widehat{T}_{i}\right)$. Now, for a wage $w<T_{i}$, we have $J_{i}>V_{i}^{S}\left(w \mid w<T_{i}\right)$, while for a wage $w \geq T_{i}$, we have $J_{i}<V_{i}^{S}(w \mid$ $\left.w \geq T_{i}\right)$. Therefore, the reservation wage is $R_{i}=T_{i}\left(<\widehat{T}_{i}\right)$.

Finally, panel $(c)$ depicts the case with $T_{i} \in\left(\widehat{T}_{i}, \bar{w}\right)$. Now, the reservation wage $R_{i}$ solves $J_{i}=V_{i}^{S}\left(w \mid w<\widehat{T}_{i}\right)$, with $R_{i}<\widehat{T}_{i}\left(<T_{i}\right)$ and $R_{i}$ decreasing in $T_{i}$.

Making use of the above, we are ready to characterise the male reservation wage for the range of female reservation matches for which the marriage market does indeed affect labour market decisions, in the sense that unemployed men choose their optimal strategy given a binding marriageability constraint. 
Proposition 1 For $T_{i} \in(\underline{R}, \bar{w}]$, the optimal strategy has the reservation wage property. The reservation wage function $R_{i}\left(T_{i}\right)$ solves

$$
R_{i}\left(T_{i}\right)=\min \left\{w: V_{i}^{S}(w) \geq J_{i}\right\}
$$

it is continuous and piecewise differentiable, with:

(i) $R_{i}=T_{i}$ for $T_{i} \in\left(\underline{R}, \widehat{T}_{i}\right]$;

(ii) $R_{i}<T_{i}$ and decreasing in $T_{i}$ for $T_{i} \in\left(\widehat{T}_{i}, \bar{w}\right]$;

(iii) $R_{i}=\underline{R}$ for $T_{i}=\bar{w}$.

Proof. We address $(i)$ first. Recall that $\widehat{T}_{i}$ is the $T_{i}$ for which $J_{i}\left(T_{i}\right)=\frac{w}{r+\delta}$ at $w=T_{i}$. When $T_{i}=\widehat{T}_{i}$ the optimal policy is a reservation wage $R_{i}$ and $R_{i}=T_{i}$ as $V_{i}^{S}\left(w \mid w<T_{i}\right)<J_{i}$ for $w<\widehat{T}_{i}$ and $V_{i}^{S}\left(w \mid w \geq T_{i}\right)>J_{i}$ for $w \geq \widehat{T}_{i}$. Also consult Panel $(b)$ in Figure 1 .

As $T_{i}$ decreases, $J_{i}\left(T_{i}\right)$ increases and $\frac{T_{i}}{r+\delta}$ decreases. For a small decrease in $T_{i}$, we have $J_{i}>V_{i}^{S}\left(w \mid w<T_{i}\right)$ and $J_{i}<V_{i}^{S}\left(w \mid w \geq T_{i}\right)$, so the reservation wage equals $T_{i}$. Define $\widetilde{T}_{i}$ as the $T_{i}$ so low that $J_{i}\left(\widetilde{T}_{i}\right)=V_{i}^{S}\left(w \mid w=\widetilde{T}_{i}\right)$. It is easy to show (see Appendix 1) that $\widetilde{T}_{i}<\underline{R}$, and hence $V_{i}^{S}\left(w \mid w \geq T_{i}\right)>J_{i}$ for $T_{i} \in\left[\underline{R}, \widehat{T}_{i}\right]$. It then follows that $R_{i}=T_{i}$ for $T_{i} \in\left(\underline{R}, \widehat{T}_{i}\right]$. Also consult Panel $(a)$ of Figure 1.

To address $(i i)$, start at $T_{i}=\widehat{T}_{i}$, where $\frac{T_{i}}{r+\delta}=J_{i}\left(T_{i}\right)$, and consider an increase in $T_{i}$. Then, $\frac{T_{i}}{r+\delta}$ increases and $J_{i}\left(T_{i}\right)$ decreases. Since the discontinuity in $V_{i}^{S}(w)$ moves rightward, it follows that $J_{i}=V_{i}^{S}\left(w \mid w<T_{i}\right)$ holds for a wage lower than $T_{i}$. This is our reservation wage $R_{i}$, which clearly decreases as $T_{i}$ increases. Consult Panel $(c)$ in Figure 1 this time. Finally, when $T_{i}=\bar{w}$, we have $F\left(T_{i}\right)=1$ and the problem reverts to one of standard job search. One can also conclude that the optimal reservation wage is continuous in $T_{i}$, with a corner at $\widehat{T}_{i}$.

Please also note that in the case of constrained sequential job search the condition that determines $R_{i}$ can sometimes hold with strict inequality. This is also due to the discontinuity in the value of accepting a job.

With our focus being on beauty premium and marriage premium, and given the natural link between reservation wages and average wages earned by men, we are particularly interested in the reservation wage $R_{i}$ for $T_{i} \in\left(\widehat{T}_{i}, \bar{w}\right]$. 
Remark 1 For $T_{i} \in\left(\widehat{T}_{i}, \bar{w}\right]$,

$$
R_{i}=\frac{\lambda_{0}}{r+\delta}\left[\int_{R_{i}}^{\bar{w}}[1-F(w)] d w+\frac{\left[1-F\left(T_{i}\right)\right] \lambda n}{r+\delta+\lambda n} y\right] \quad\left(<T_{i}\right) .
$$

Proof. From Proposition 1, we know that $R_{i}<T_{i}$ in that range. Hence, $V_{i}^{S}\left(R_{i}\right)=\frac{R_{i}}{r+\delta}$. From the proof of Proposition $1, V_{i}^{S}\left(R_{i}\right)=J_{i}$, so the reservation wage solves:

$$
\begin{gathered}
\frac{R_{i}}{r+\delta}=\frac{\lambda_{0}}{r+\delta+\lambda_{0}} F\left(R_{i}\right) \int_{\underline{w}}^{R_{i}} \frac{R_{i}}{r+\delta} d F\left(w \mid w<R_{i}\right)+ \\
+\frac{\lambda_{0}}{r+\delta+\lambda_{0}}\left[F\left(T_{i}\right)-F\left(R_{i}\right)\right] \int_{R_{i}}^{T_{i}} \frac{w}{r+\delta} d F\left(w \mid R_{i}<w<T_{i}\right)+ \\
+\frac{\lambda_{0}}{r+\delta+\lambda_{0}}\left[1-F\left(T_{i}\right)\right] \int_{T_{i}}^{\bar{w}}\left[\frac{w}{r+\delta}+\frac{\lambda n}{(r+\delta)(r+\delta+\lambda n)} y\right] d F\left(w \mid w>T_{i}\right) .
\end{gathered}
$$

After some manipulations (please consult Appendix 2), this simplifies to:

$$
R_{i}=\frac{\lambda_{0}}{r+\delta} \int_{R_{i}}^{\bar{w}}\left[w-R_{i}\right] d F(w)+\frac{\lambda_{0}\left[1-F\left(T_{i}\right)\right] \lambda n}{(r+\delta)(r+\delta+\lambda n)} y
$$

Integrating by parts, we obtain our $R_{i}$.

A closer look at (3) reveals that the right-hand side of the expression is standard: the reservation wage must compensate for the loss of the option of continued search for better job offers. The second term pertains to the man's options in the marriage market. The possibility of contacting (at rate $\lambda_{0}$ ) a firm that offers a wage which confers marriageability (probability $1-F\left(T_{i}\right)$ ), and subsequently meeting a woman (at rate $\lambda n$ ) would lead to flow payoff $y$. If a type $i$ unemployed man were to accept a wage $w$ less than $T_{i}$, he would be giving up the option of utility from marriage. Therefore, the reservation wage must compensate for this loss as well.

For $T_{i}>\widehat{T}_{i}$, the optimal reservation wage given by (3) solves $\frac{R_{i}}{r+\delta}=J_{i}$. Intuitively, the value of working at the reservation wage (which here precludes 
marriage) must be equal to the value of continued job search. This is not the case at $T_{i}=\widehat{T}_{i}$ since then, as shown in Proposition 1, the optimal strategy is to set $R_{i}$ equal to $T_{i}$, meaning that working at this reservation wage does not now preclude marriage. Despite the fact that (3) does not describe the optimal strategy in this latter case, we can obtain $\widehat{T}_{i}$ by imposing $R_{i}=T_{i}$ in this equation. The reason one can do this is that the reservation wage $R_{i}$ implicitly defined by (3) is in fact continuous at $T_{i}=R_{i}$. Because of this, one can also obtain:

$$
\widehat{T}_{i}=\frac{\lambda_{0}}{r+\delta}\left[\int_{\widehat{T}_{i}}^{\bar{w}}[1-F(w)]+\frac{\left[1-F\left(\widehat{T}_{i}\right)\right] \lambda n}{r+\delta+\lambda n} y\right] \quad(>\underline{R}) .
$$

Up to now (consult Figure 1 as well), we have implicitly assumed that $\widehat{T}_{i}<\bar{w}$. Using $\widehat{T}_{i}$ above, we can now also establish that as long as there are search frictions in the labour market, $\widehat{T}_{i}$ is indeed less than $\bar{w}$. This means there is always a range of $T_{i}$ for which $R_{i}<T_{i}$, with $R_{i}$ decreasing in that range.

Remark 2 Given $\lambda_{0}<\infty$, and for any $y<\infty$, we have $\widehat{T}_{i}<\bar{w}$.

Proof. If there are no search frictions in the labour market $\left(\lambda_{0} \rightarrow \infty\right)$, then $R_{i}\left(T_{i}\right)=\bar{w}$.

Next, note that $\widehat{T}_{i}$ is a function of $y$. Since $\frac{\partial F\left(\widehat{T}_{i}\right)}{\partial \widehat{T}_{i}}>0$, we have:

$$
\frac{\partial \widehat{T}_{i}}{\partial y}=\frac{\lambda_{0} \lambda n\left[1-F\left(\widehat{T}_{i}\right)\right]}{(r+\delta+\lambda n)\left[r+\delta+\lambda_{0}\left[1-F\left(\widehat{T}_{i}\right)\right]\right]+\lambda_{0} \lambda n \frac{\partial F\left(\widehat{T}_{i}\right)}{\partial \widehat{T}_{i}} y}>0 .
$$

One can solve for $y$ to get:

$$
y=\frac{(r+\delta+\lambda n)\left[(r+\delta) \widehat{T}_{i}-\lambda_{0} \int_{\widehat{T}_{i}}^{\bar{w}}[1-F(w)] d w\right]}{\lambda_{0} \lambda n\left[1-F\left(\widehat{T}_{i}\right)\right]} .
$$

Then, $\lim _{\widehat{T}_{i} \rightarrow \bar{w}} y=\infty$, since the limit of the numerator is a positive constant, while the limit of the denominator is zero. As $\widehat{T}_{i}$ is an invertible function, it follows immediately that $\lim _{y \rightarrow \infty} \widehat{T}_{i}=\bar{w}$. 
The next Proposition completes the characterisation of the reservation wage function $R_{i}\left(T_{i}\right)$. It describes the optimal policy in the face of female reservation matches that are either too low or too high to matter for decisions in the labour market. The former pertains to a situation where all men (employed or unemployed) can get married, while the latter covers the scenario where no man is ever acceptable to women.

Proposition 2 For $T_{i} \leq \underline{R}$ and $T_{i}>\bar{w}$ the optimal strategy has the reservation wage property, and the reservation wage is $\underline{R}$.

Proof. Once married, an unemployed man would drop his reservation wage to $\underline{R}$, but if $T_{i} \leq \underline{R}$ a woman is willing to marry such a man anyway. Recall that $J_{i}^{M}=\frac{R+y}{r+\delta}$ and let $J_{i}^{\prime}$ denote the value of a single unemployed man in this scenario.

For any optimally chosen reservation wage $R_{i}^{\prime}$ that is higher than $T_{i}$ (or equal) we have $V_{i}^{S}\left(w \mid w \geq T_{i}\right)$ for any acceptable offer, which is continuous in $w$. We can therefore write $J_{i}^{\prime}$ using the standard asset pricing equation:

$(r+\delta) J_{i}^{\prime}=\lambda n\left[J_{i}^{M}-J_{i}^{\prime}\right]+\lambda_{0} \int_{R_{i}^{\prime}}^{\bar{w}}\left[\frac{w}{r+\delta}+\frac{\lambda n}{(r+\delta)(r+\delta+\lambda n)} y-J_{i}^{\prime}\right] d F(w)$,

with the reservation wage $R_{i}^{\prime}$ solving $V_{i}^{S}\left(R_{i}^{\prime}\right)=J_{i}^{\prime}$. It is easy to show that $\underline{R}$ is indeed higher than $T_{i}$ and satisfies $V_{i}^{S}(\underline{R})=J_{i}^{\prime}$, so $R_{i}^{\prime}=\underline{R}$. Finally, for $T_{i}>\bar{w}$, we have $F\left(T_{i}\right)=1$ and the problem reverts to one of standard job search.

Note that $\widehat{T}_{H}=\widehat{T}_{L} \equiv \widehat{T}$ and, since men face the same wage distribution (as well as the other relevant structural parameters), their reservation wage functions are also identical: for any $T$, we have $R_{L}(T)=R_{H}(T) \equiv R(T)$. Of course, the two optimal reservation wages $R_{i}$ may still be different, as they are simply the reservation function evaluated at the two reservation matches chosen by the women. That is, $R_{i}=R\left(T_{i}\right)$.

The reservation wage function of unemployed men is illustrated in Figure 2. The diagram shows that their best response function is non-monotonic and attains its maximum value when $T=\widehat{T}$, where $\widehat{R}=R(\widehat{T})=\widehat{T}$.

This non-monotonicity captures an interesting trade-off faced by men, for varying levels of $T$. The trade-off stems from the fact that when the 
marriage problem is not trivial, an increase in the male reservation wage has two effects. On the one hand, it confers marriageability - if it satisfies women's reservation match. On the other hand, any increase in reservation wage comes at the cost of limiting your job prospects.

If the female reservation match is relatively low (but still above $\underline{R}$ ), the cost mentioned above is not too high, and therefore men hold out for such a wage. However, this cost increases with $T$ and there is a threshold value $(\widehat{T})$ for which this negative effect is no longer compensated by the prospect of marriage.

For $T \in(\widehat{T}, \bar{w})$, by setting a reservation wage lower than what women require, a single man risks throwing away the prospect of marriage. Nonetheless, he is willing to accept this risk purely because of search frictions and what one might call the "bird in hand" effect. Now, a job offer is deemed acceptable by an unemployed single man even if it precludes marriage. A wage may well be less than the (relatively high) threshold set by women. At the same time however, it may be sufficiently high so that an unemployed turns down the option of holding out for even higher (but unlikely) offers. For higher and higher female reservation matches the likelihood of encountering such high wages decreases further and with it, men's reservation wage.

Of course, a single man who sets a low reservation wage may still be able to get married if he is lucky and lands a good job.

\subsection{Women}

For women active in the marriage market, the relevant parameters are the measure of eligible (marriageable) men and the distribution of wages earned by these men. Together, they determine the arrival rates of acceptable marriage partners and the available wage prospects. For this reason, we start the section by looking at the steady state conditions for our economy.

\subsubsection{Steady state}

The inflow of unemployed who find jobs with marriageable wages (equal or above $\left.T_{i}\right)$, and the outflow from the stock of these eligible men $\left(N_{i}\right)$ are the same when:

$$
u_{i} \lambda_{0}\left[1-F\left(T_{i}\right)\right]=N_{i}(\lambda n+\delta)
$$


That is, eligible (marriageable) men of type $i$ get married at rate $\lambda n$ and exit the economy at rate $\delta$, while unemployed men find suitable wages that permit marriage at rate $\lambda_{0}\left[1-F\left(T_{i}\right)\right]$. From here,

$$
N_{i}=\frac{u_{i} \lambda_{0}\left[1-F\left(T_{i}\right)\right]}{\lambda n+\delta} .
$$

Denote by $G_{i}(w)$ the distribution of wages earned by eligible men. It is obtained by combining the expression for $N_{i}$ above with the steady-state equation below:

$$
u_{i} \lambda_{0}\left[F(w)-F\left(T_{i}\right)\right]=N_{i} G_{i}(w)[\lambda n+\delta] .
$$

This equates the flow into employment at wages lower than $w$ but higher than $T_{i}$ (which allow for marriage), and the outflow (through marriage or exit) from this stock of men. We obtain:

$$
G_{i}(w)=\frac{F(w)-F\left(T_{i}\right)}{1-F\left(T_{i}\right)} .
$$

For completeness, and because it will be of use later, we also solve for the steady state measures of bachelors $\left(B_{i}\right)$ and of married men $\left(M_{i}\right)$, as well as the distribution of wages amongst these two groups of men. First, note that $B_{i}$ solves:

$$
u_{i} \lambda_{0}\left[F\left(T_{i}\right)-F\left(R_{i}\right)\right]=\delta B_{i} .
$$

These are the men who have accepted jobs with wages lower than $T_{i}$, and who exit this pool at rate $\delta$.

Denote by $H_{i}(w)$ the distribution of wages amongst bachelors. Then,

$$
u_{i} \lambda_{0}\left[F(w)-F\left(R_{i}\right)\right]=\delta B_{i} H_{i}(w),
$$

and we obtain:

$$
H_{i}(w)=\frac{F(w)-F\left(R_{i}\right)}{F\left(T_{i}\right)-F\left(R_{i}\right)}
$$

In turn, $M_{i}$ solves:

$$
\lambda n N_{i}=\delta M_{i} .
$$

Since the rate at which eligible single men $\left(N_{i}\right)$ get married is independent of their wage, and the rate at which married men $\left(M_{i}\right)$ leave the economy is also independent of the wage they earn, the distribution of wages for the latter group is also $G_{i}(w)$. 


\subsubsection{Reservation match}

Given sequential search in the marriage market, we show that the optimal strategy for women has the reservation value or match property. But, as wages and looks are perfect substitutes, and since women regard men as either attractive or less attractive, they in fact use a reservation wage strategy $T_{i}\left(z_{i}\right)$, rejecting men of type $i$ who earn a wage less than $T_{i}\left(z_{i}\right)$.

With $w+z_{i}$ being the flow utility of a woman who is married to a type $i$ employed man with wage $w$, the key observation is that women have a unique threshold reservation match (value). Crucially however, this reservation match can be fulfilled differently by the two types of men. In other words, even a less attractive man can get married as long as he earns enough. Enough here means of course a wage sufficiently higher than that of his more attractive rivals. However, as we have seen, whether he does or does not earn such a wage will depend on the job offers he encounters and chooses to accept.

Recall that the value of being married to a type $i$ man who earns a wage $w$ is $W_{i}^{M}(w)=\frac{w+z_{i}}{r+\delta}$. This value is continuous and increasing for any wage. Let $W^{S}$ denote the expected value of being a single woman. Since it is independent of any $w$, women's reservation wage $T_{i}$ is obtained in the standard way. Again, we focus on the scenario with $T_{i}>\underline{R}$, when women do not marry type $i$ unemployed men (recall Lemma 1 ). First, note that $W^{S}$ is given by:

$$
\begin{aligned}
& (1+r \Delta) W^{S}=x \Delta+(1-\delta \Delta)\left(1-\lambda_{w}^{H} \Delta\right)\left(1-\lambda_{w}^{L} \Delta\right)\left[\left(1-\lambda_{w}^{u} \Delta\right)+\lambda_{w}^{u} \Delta\right] W^{S}+ \\
& \quad+(1-\delta \Delta)\left(1-\lambda_{w}^{L} \Delta\right) \lambda_{w}^{H} \Delta\left(1-\lambda_{w}^{u} \Delta\right) \int_{\underline{w}}^{\bar{w}} \max \left\{W_{H}^{M}(w), W^{S}\right\} d F(w)+ \\
& +(1-\delta \Delta)\left(1-\lambda_{w}^{H} \Delta\right) \lambda_{w}^{L} \Delta\left(1-\lambda_{w}^{u} \Delta\right) \int_{\underline{w}}^{\bar{w}} \max \left\{W_{L}^{M}(w), W^{S}\right\} d F(w)+o(\Delta) .
\end{aligned}
$$

During the current period, a single woman enjoys the flow payoff $x$. Provided she survives into the next period, she faces the following scenarios: (i) she does not meet anyone and therefore stays on the value $W^{S}$, (ii) she only encounters an unemployed man (of either type) whom she turns down and again retains $W^{S}$, or (iii) meets only a type $i=H, L$ employed man who 
earns a wage $w$, so the woman's payoff in that case is given by her expected continuation value. Meeting two men in a very short period of time is of course a zero probability event.

Suitably rearranging the above, dividing by $\Delta$ and taking limits, we obtain:

$$
\begin{gathered}
(r+\delta) W^{S}=x+\lambda_{w}^{H} \int_{\underline{w}}^{\bar{w}} \max \left\{W_{H}^{M}(w)-W^{S}, 0\right\} d F(w)+ \\
+\lambda_{w}^{L} \int_{\underline{w}}^{\bar{w}} \max \left\{W_{L}^{M}(w)-W^{S}, 0\right\} d F(w) .
\end{gathered}
$$

Using $\lambda_{w}^{i}=\lambda N_{i}$, the steady state condition for $N_{i}$, as well as the definition of a reservation match $(r+\delta) W^{S}=T_{i}+z_{i}$, we have:

$$
\begin{gathered}
(r+\delta) W^{S}=x+\frac{\lambda u_{H} \lambda_{0}\left[1-F\left(T_{H}\right)\right]}{\lambda n+\delta} \int_{T_{H}}^{\bar{w}}\left[W_{H}^{M}(w)-W^{S}\right] d G_{H}(w)+ \\
+\frac{\lambda u_{L} \lambda_{0}\left[1-F\left(T_{L}\right)\right]}{\lambda n+\delta} \int_{T_{L}}^{\bar{w}}\left[W_{L}^{M}(w)-W^{S}\right] d G_{L}(w) .
\end{gathered}
$$

Alternatively, given that $G_{i}(w)=\frac{F(w)-F\left(T_{i}\right)}{1-F\left(T_{i}\right)}$, one can rewrite this as:

$$
\begin{gathered}
(r+\delta) W^{S}=x+\frac{\lambda u_{H} \lambda_{0}}{(\lambda n+\delta)} \int_{T_{H}}^{\bar{w}}\left[W_{H}^{M}(w)-W^{S}\right] d F_{H}(w)+ \\
+\frac{\lambda u_{L} \lambda_{0}}{(\lambda n+\delta)} \int_{T_{L}}^{\bar{w}}\left[W_{L}^{M}(w)-W^{S}\right] d F_{L}(w) .
\end{gathered}
$$

As before, the left-hand side is the flow value for a single woman. On the right-hand side, we have her instantaneous utility $x$ plus the expected increase in utility that obtains from any change in the value of her state, which in this case is the probability that she meets a marriageable type $i$ employed man times the expected increase in value.

Lemma $2 T_{H}<T_{L}$.

Proof. With $z_{H}>z_{L}$, it follows immediately from the definition of the reservation match: $(r+\delta) W^{S}=T_{H}+z_{H}=T_{L}+z_{L}$. 
Note that $W^{S}$ and therefore $T_{i}$ are in fact independent of men's search strategy $R_{i}$. This is essentially due to the fact that the wage distribution is exogenous. Men's reservation wage strategy has no impact on $F($.$) , and$ nor does it affect the rate at which unemployed find wages that permit marriage. Furthermore, from the steady state equation for $N_{i}$ it is clear that the measure of eligible men $\left(N_{i}\right)$ is also independent of $R_{i}$.

\section{Equilibrium}

In what follows we establish the existence and provide a full characterisation of the possible search equilibria, with a particular focus on the beauty premium. Importantly, we show that the beauty premium as an equilibrium outcome is robust, in the sense that there always exist parameter values for which there are equilibria with such wage differentials.

We also show that the reservation wage strategies of unemployed men can lead to an equilibrium male marital wage gap. Furthermore, we establish the link between the beauty premium and the marriage premium for our equilibrium profiles.

Before stating the main results, we first define our equilibrium concept and provide formal definitions for beauty premium and marriage premium in the context of our model.

\subsection{Definition of search equilibrium}

A search equilibrium is a system $\left\{R_{i}, T_{i}, G_{i}(),. H_{i}(),. N_{i}, B_{i}, M_{i}, u_{i}\right\}$ satisfying the following:

(i) Men's reservation wage $R_{i}$ is given by:

$$
\begin{aligned}
& R_{i}=\frac{\lambda_{0}}{r+\delta}\left[\int_{R_{i}}^{\bar{w}}[1-F(w)] d w+\frac{\left[1-F\left(T_{i}\right)\right] \lambda n}{r+\delta+\lambda n} y\right] \quad\left(<T_{i}\right) \quad \text { for } \widehat{T}_{i}<T_{i}<\bar{w} \\
& R_{i}=T_{i} \quad \text { for } \underline{R}<T_{i} \leq \widehat{T}_{i} \\
& R_{i}=\underline{R} \quad \text { for } T_{i}<\underline{R} \text { and } T_{i} \geq \bar{w} .
\end{aligned}
$$


(ii) Women's reservation wages $T_{i}$ satisfy:

$$
T_{i}+z_{i}=(r+\delta) W^{S}
$$

where $W^{S}$ as defined in (4).

(iii) The distribution of wages earned by eligible, married and unmarriageable type $i$ men are, respectively:

$$
G_{i}(w)=\frac{F(w)-F\left(T_{i}\right)}{1-F\left(T_{i}\right)}
$$

and

$$
H_{i}(w)=\frac{F(w)-F\left(R_{i}\right)}{F\left(T_{i}\right)-F\left(R_{i}\right)}
$$

(iv) Steady state turnover conditions:

$$
\begin{gathered}
N_{i}(\lambda n+\delta)=u_{i} \lambda_{0}\left[1-F\left(T_{i}\right)\right] \\
u_{i} \lambda_{0}\left[F(w)-F\left(T_{i}\right)\right]=N_{i} G_{i}(w)[\lambda n+\delta] \\
u_{i} \lambda_{0}\left[F\left(T_{i}\right)-F\left(R_{i}\right)\right]=\delta B_{i} \\
\lambda n N_{i}=\delta M_{i} .
\end{gathered}
$$

\subsection{Marriage premium and beauty premium}

We define the marriage wage premium amongst type $i$ men (denoted by $M P_{i}$ ) as the difference between the average wage of married type $i$ men and that of single type $i$ men.

Definition 2 The marriage premium for men of type $i$ is:

$$
M P_{i} \equiv w_{i}^{M}-w_{i}^{S},
$$

where

$$
w_{i}^{S}=\frac{B_{i}}{B_{i}+N_{i}} \int_{R_{i}}^{T_{i}} w d H_{i}(w)+\frac{N_{i}}{B_{i}+N_{i}} \int_{T_{i}}^{\bar{w}} w d G_{i}(w)
$$

and

$$
w_{i}^{M}=\int_{T_{i}}^{\bar{w}} w d G_{i}(w) .
$$


The straightforward link between male reservation wages and marital wage differences is established below:

Remark $3 M P_{i}>0$ for $R_{i}<T_{i}$, and $M P_{i}=0$ for $R_{i}=T_{i}$. Furthermore, $M P_{i}$ increases in $T_{i}-R_{i}$.

Proof. For $R_{i}=T_{i}$ we have $B_{i}=0$, and hence $w_{i}^{M}=w_{i}^{S}$. For $R_{i}<T_{i}$ we have $B_{i}>0$ and, making use of $G_{i}(w)$ and $H_{i}(w)$, it follows that $w_{i}^{M}>w_{i}^{S}$. Also, it is easy to check that $M P_{i}$ increases in $T_{i}-R_{i}$.

Note the importance of the above result: a positive male marriage premium is possible only if the region in which $R_{i}$ is decreasing in $T_{i}$ exists. In turn, as shown in Remark 2, this can only happen if there are search frictions in the labour market. Clearly, a meaningful reservation wage $T_{i}$ is only possible if there are search frictions in the marriage market.

We define the beauty premium $(B P)$ as the difference between the average wage of all (married and single) type $H$ men and the average wage of all (married and single) type $L$ men.

Definition 3 The beauty premium is:

$$
B P \equiv w_{H}-w_{L},
$$

where

$$
w_{i}=\frac{\left(B_{i}+N_{i}\right)}{B_{i}+N_{i}+M_{i}} w_{i}^{S}+\frac{M_{i}}{B_{i}+N_{i}+M_{i}} w_{i}^{M} .
$$

Next, we establish the link between male reservation wages and the beauty premium.

Remark $4 B P \gtreqless 0$ iff $R_{H} \gtreqless R_{L}$. Furthermore, BP increases in $R_{H}-R_{L}$.

Proof. Substitute $B_{i}, N_{i}, M_{i}, G_{i}(w)$ and $H_{i}(w)$ into the definition of $B P$ above. 


\subsection{Search equilibria}

As we are interested in outcomes that can only obtain as a result of optimal strategies being influenced by decisions in both markets, we restrict our attention to the case where $T_{i} \geq \underline{R}$ for $i=H, L$. Indeed, this will later constitute the core of our empirical analysis. ${ }^{7}$

We consider the range of parameters $x$ and $z_{i}$ for which the set of possible search equilibrium types is largest. First, without any loss of generality, normalise $z_{L}$ to zero and let $z_{H}=T_{L}-T_{H} \equiv z$. Next, assume that $z<\bar{w}-\underline{R}$, so it is indeed possible that the labour market behaviour of both types of men is affected by their prospects in the marriage market.

Note that although $\underline{R}$ and $\widehat{T}$ are endogenous, they are in fact independent of $x$ and $z$.

Definition 4 Consider the following threshold values of $x$ and $z$ :

$x_{1}$ such that $T_{H}=\underline{R}$;

$x_{2}$ such that $T_{L}=\widehat{T}$;

$x_{3}$ such that $T_{H} \in(\underline{R}, \widehat{T}), T_{L} \in(\widehat{T}, \bar{w})$ and $R_{L}=T_{H}=R_{H}$;

$x_{4}$ such that $T_{H}=\widehat{T}$;

$x_{5}$ such that $T_{L}=\bar{w}$;

$x_{6}$ such that $T_{H}=\bar{w}$;

$z_{1}=\bar{w}-\widehat{T}$

$z_{2}=\widehat{T}-\underline{R}$.

Note that $x_{3}$ exists for $z<\bar{w}-\underline{R}$. In addition, only if $z<z_{1}$ is it possible that both $T_{H}$ and $T_{L}$ belong to the same interval $(\widehat{T}, \bar{w})$. In turn, only if $z<z_{2}$ is it possible that both $T_{H}$ and $T_{L}$ belong to the same interval $(\underline{R}, \widehat{T})$.

Next, we list all possible types of equilibria, each characterised by beauty premium and marriage premium profiles.

${ }^{7}$ Extending our results (and proving existence of an equilibrium) for $T_{i}<\underline{R}$ is not difficult. However, it involves a tedious derivation of $W^{S}$, and then $T_{i}$, for $T_{i}$ supposedly lower than $\underline{R}$, while the equilibrium itself is uninteresting. 
Definition 5 Let:

Equilibrium $A: B P<0$, and $M P_{H}=M P_{L}=0$;

Equilibrium $B: B P<0$, and $M P_{H}=0, M P_{L}>0$;

Equilibrium $C: B P=0$, and $M P_{H}=0, M P_{L}>0$;

Equilibrium $D: B P>0$, and $M P_{H}=0, M P_{L}>0$;

Equilibrium E: $B P>0$, and $M P_{L}>M P_{H}>0$;

Equilibrium $F: B P>0$ and $M P_{H}>0$, with $L$ type men unable to marry;

Equilibrium $G$ : $B P=0$, with both types of men unable to marry.

We are ready to state our main result.

Theorem 1 Given $x \geq x_{1}$, the set of possible equilibrium configurations is largest if $z<z_{1}$. Then:

(a) For $x \in\left(x_{3}, x_{6}\right]$, an unique equilibrium with $B P>0$ exists, as follows:

Equilibrium D obtains for $x \in\left(x_{3}, x_{4}\right]$;

Equilibrium $E$ obtains for $x \in\left(x_{4}, x_{5}\right]$;

Equilibrium $F$ obtains for $x \in\left(x_{5}, x_{6}\right]$.

(b) For $x=x_{3}$ and $x \in\left(x_{6}, \infty\right)$, an unique equilibrium with $B P=0$ exists, as follows:

Equilibrium $C$ obtains for $x=x_{3}$;

Equilibrium $G$ obtains for $x \in\left(x_{6}, \infty\right)$.

(c) For $x \in\left[x_{1}, x_{2}\right]$ and $x \in\left(x_{2}, x_{3}\right)$, an unique equilibrium with $B P<0$ exists, as follows:

Equilibrium $A$ obtains for $x \in\left[x_{1}, x_{2}\right]$;

Equilibrium $B$ obtains for $x \in\left(x_{2}, x_{3}\right)$;

For $z \geq z_{1}$, Equilibrium $E$ does not exist.

Proof. With $R(T)$ continuous and $T_{i}$ independent of $R_{i}$, an unique equilibrium always exists for $x>x_{1}$. From Remark $2, \widehat{T}<\bar{w}$. Note that $\partial T_{i} / \partial x>0$ for $i=H, L$. From Lemma 2 we have $T_{H}<T_{L}$, and therefore $x_{1}<x_{2}<x_{3}<x_{4}<x_{5}<x_{6}$ for $z<z_{1}$ and $z<z_{2}$. Using the results in Propositions 1 and 2, as well as Remarks 3 and 4, it follows that:

For $x \in\left[x_{1}, x_{2}\right]$ both $T_{H}$ and $T_{L}$ belong to $(\underline{R}, \widehat{T}]$, so $M P_{H}=M P_{L}=0$. Furthermore, $R_{H}<R_{L}$ so $B P<0$. Equilibrium $A$ obtains.

For $x \in\left(x_{2}, x_{3}\right)$ we have $T_{H} \in(\underline{R}, \widehat{T}), T_{L} \in(\widehat{T}, \bar{w})$, so $M P_{H}=0, M P_{L}>$ 0 . Furthermore, $R_{H}<R_{L}$ so $B P<0$. We have equilibrium $B$.

For $x=x_{3}$ we have $T_{H} \in(\underline{R}, \widehat{T}), T_{L} \in(\widehat{T}, \bar{w})$, so $M P_{H}=0, M P_{L}>0$. Furthermore, $\underline{R}<R_{H}=R_{L}$ so $B P=0$. Equilibrium $C$ results. 
For $x \in\left(x_{3}, x_{4}\right]$ we have $T_{H} \in(\underline{R}, \widehat{T}], T_{L} \in(\widehat{T}, \bar{w})$, so $M P_{H}=0, M P_{L}>0$. Furthermore, $R_{H}>R_{L}$ so $B P>0$. We are in equilibrium $D$.

For $x \in\left(x_{4}, x_{5}\right]$ both $T_{H}$ and $T_{L}$ belong to $(\widehat{T}, \bar{w}]$, so $M P_{H}>0, M P_{L}>0$. Furthermore $R_{H}>R_{L}(>\underline{R})$ so $B P>0$. This is equilibrium $E$.

For $x \in\left(x_{5}, x_{6}\right]$ we have $T_{H} \in(\widehat{T}, \bar{w}]$ and $T_{L}>\bar{w}$ so $M P_{H}>0$ and type $L$ men never marry. $B P>0$ since $R_{H}>R_{L}=\underline{R}$, so we are in the $F$ equilibrium.

For $x \in\left(x_{6}, \infty\right)$ we have $T_{H}>\bar{w}$ and $T_{L}>\bar{w}$, so $R_{H}=R_{L}=\underline{R}$ and no men get married. Equilibrium $G$ results.

For $z \geq z_{2}$, as $T_{H}$ and $T_{L}$ cannot belong to the same interval $(\underline{R}, \widehat{T}]$, equilibrium $A$ cannot obtain for $x>x_{1}$. For $z \geq z_{1}, T_{H}$ and $T_{L}$ cannot belong to the same interval $(\widehat{T}, \bar{w}]$, therefore equilibrium $E$ does not survive.

Figure 2 illustrates all the above, and depicts Equilibrium E, which is characterised by a positive beauty premium.

FIGURE 2 (please see at the end of paper)

Anticipating our empirical investigation, the following three Corollaries establish some further interesting results.

Corollary 1 looks at the robustness of equilibria with positive beauty premium. Corollary 2 discusses equilibrium marriage rates, while Corollary 3 establishes the subtle relationship between the two types of premia ( $B P$ and $M P$ ) across different equilibrium configurations. 
Corollary 1 The set of parameter values for which a search equilibrium with positive beauty premium exists is not empty.

Proof. Equilibrium $F$ exists for any $z<\infty$; equilibrium $D$ exists for any $z<\bar{w}-\underline{R}$; equilibrium $E$ exists for $z<z_{1}$.

Note that equilibrium $F$ could be interpreted as a version of equilibrium $E$ with restricted trade, when $T_{L}$ is so high that there is no possibility of marriage for type $L$ men.

Corollary $2(i)$ For $T_{i} \in(\underline{R}, \widehat{T}]$, the marriage rate of type $i$ unemployed men is zero, while the marriage rate of type $i$ employed men is independent of their wage.

(ii) For $T_{i} \in(\widehat{T}, \bar{w}]$ the marriage rate of type $i$ unemployed men is zero, while the marriage rate of type $i$ employed men is an increasing step function of their wage.

Proof. From Lemma 1, type $i$ unemployed cannot get married if $T_{i}>\underline{R}$. From Proposition 1 , when $T_{i} \in(\underline{R}, \widehat{T}]$, we have $R_{i}=T_{i}$ and all employed men get married at rate $\lambda n$. In turn, for $T_{i} \in(\widehat{T}, \bar{w}]$, we have $R_{i}<T_{i}$, and therefore only employed men with wage higher than $T_{i}$ (or equal) get married, and do so at rate $\lambda n$.

Corollary $3(i)$ In any equilibrium, $M P_{H} \leq M P_{L}$, with strict inequality if $M P_{L}>0$.

(ii) In any equilibrium with $B P>0$, we have that either $M P_{L}>0$ or $L$ type men never marry.

(iii) In any equilibrium with marriage and $B P=0$ we have $M P_{H}=0$.

Proof. All follow from inspection of equilibrium configurations in the Theorem. 


\section{Empirical test}

In this section we carry out a falsification test of the theory and consider further evidence in support of our search theoretic approach. In order to do this, we exploit the links between marriage premia, beauty premium and marriage rates as summarised in Corollaries (2) and (3). Using British data, we estimate the two types of wage differentials across male workers who differ in terms of anthropometric characteristics. Following the literature, we use height and weight (body mass index BMI) as proxies for physical attractiveness.

Strictly speaking, if we find evidence in favour of any of the three tests below, our theory would be refuted. In particular, our theoretical approach would fail the strict falsification test if, when using height or weight (BMI) as proxy for beauty...

Test 1: ...we find that either $(a)$ the marriage wage premium for short (obese) men is zero while the marriage wage premium for tall (non-obese) men is positive, or $(b)$ the marriage wage premium for short (obese) men is positive and the marriage wage premium for tall (non-obese) is not lower. Either of these findings would contradict the theoretical predictions exposed in Corollary 3(i).

Test 2: ...we find that the beauty premium is positive and the marriage wage premium for short (obese) men is not positive. This would contradict the theoretical predictions contained in Corollary 3(ii).

Test 3: ...we find a zero beauty premium, but the marriage premium for tall (non obese) men is different from zero. This would contradict Corollary $3($ iii $)$.

We first estimate the beauty premium in our samples, then check for the existence and pattern of marriage premia among different groups of men. Results are presented in detail and discussed below, but we note here that the estimates (especially when we use height) are very much in line with the theoretical predictions. Importantly, our findings also seem to confirm the inter-dependence of decisions across the two markets. Further evidence in support of the search theoretical approach is provided by the estimates for marriage rates as a function of employment status and wages. 


\subsection{Data and summary statistics}

We use data from the British Household Panel Survey (BHPS) from Great Britain. The BHPS is a longitudinal panel survey that was first collected in 1991, with the last wave obtained in $2008 .{ }^{8}$

Initially the BHPS interviewed 5,000 households, providing around 10,000 interviews. The same individuals are interviewed each year, and if individuals split off from their original household into a new household then all members of the new household are also interviewed. The data is supplemented by extra samples covering geographical areas of Great Britain. The BHPS includes rich information on income and socio-economic status, making it ideal for estimating wage equations.

For all the empirical models below the dependent variable is the log of monthly labour income from last month. There is no variable in the BHPS for the hourly wage and while it is possible to construct such a variable, doing so risks reducing the sample size and introducing error in the measurement. We only include men who had labour income in the last month before their interview. Our focus is on men who are either in their first marriage or have not yet married. In this case individuals described as 'living as a couple' are considered as non-married. Results from alternative specifications of the models that have these individuals dropped from the sample are very similar.

As relevant proxies for beauty (attractiveness), we use measures of height and weight (body mass index BMI). Our preferred measure is height due to its time invariant nature and the fact that a large empirical literature supports the idea that height is positively correlated with earnings and marital outcomes. In contrast, weight is not time invariant and so it is possible that the BMI at the time of matching is different to the BMI recorded in the data. This is to be expected to a certain extent if men pay less attention to their BMI once married (see Averett et al., 2008). As a consequence, the empirically observed relationship between weight and marriage rates is less

${ }^{8}$ The BHPS respondents have subsequently been included in the Understanding Society longitudinal study that is currently three waves old. BHPS respondents were not included in the first wave and the attrition has been particularly high. 
robust. In addition, the existing empirical literature shows that the correlation between BMI and wage is ambiguous.

The BHPS only collected data on weight and height in waves 14 and 16 . Heights and weights were measured in either metric or imperial units, but for this paper all measures were converted to metric units. We treat height as time invariant. When classifying individuals by height we are able to use the height measurements for each individual in waves 14 and 16 and apply those heights to all waves in which the individuals appear, providing a much larger sample size.

For each measure of beauty we categorize two groups: the attractive (tall or not obese) and the not attractive (not tall or obese).

Initially, individuals are classified as "not tall" if their height is 1.70 metres or less. The average height of our estimation sample is 1.78 metres, which is roughly the average height for men in Great Britain. To check for robustness we alter the threshold height of "not tall" to include taller individuals and then repeat the empirical exercise.

For BMI, we split the sample into "obese" (BMI greater than or equal to 30) and "not obese" (BMI below 30). ${ }^{9}$ For the sample in 2004 the average BMI was 26.51, but by 2006 it had increased to 26.8 .

We focus on men aged between 20-50, although we investigate the impact of using different age groups as well.

All models include controls for age, education, self-reported health (potentially another source of productivity), race, a regional dummy, year dummies and a range of job specific factors such as: experience, a dummy identifying sector of employment, social class, occupational classification, number of employees and markers of union status.

We only report results for the dummies related to marital status and anthropometric characteristics (height and weight). All other variables are included as controls and the results are available on request.

\footnotetext{
${ }^{9}$ There are potential difficulties in how to classify individuals with very low BMI, whether they are they attractive or not. For our models we removed individuals with a BMI of less than 20 .
} 
After the deletion of missing values on variables we are left with 3001 individuals (17060 observations) for the height regressions and 1706 individuals (2454 observations) for the weight regressions.

The summary statistics for our samples are given in Table 1 below:

TABLE 1 ABOUT HERE (please see at the end of paper)

Looking at the samples grouped by height and by BMI, one can identify distinct differences in the characteristics of individuals. Table 2 below summarises this.

TABLE 2a) and 2b) ABOUT HERE (please see at the end of paper)

From the two tables above one can see that the "tall" and the "not obese" are, on average, younger and more likely to report good health. Tall individuals earn, on average, more than those who are not tall. On the other hand, the average wage for the obese and not obese are quite similar. The latter may be down to the fact that the obese are typically older than the not obese men.

There are interesting differences in the proportion of married men. When comparing "tall" with "not tall" the proportion of married men is quite similar, at around $63 \%$. However, there are larger differences in the proportion of married men when they are categorised by weight: $57 \%$ of "not obese" men are married, compared to $70 \%$ of "obese" men. Again, this may be the effect of age. 


\subsection{Analysis and results}

In what follows, we present in detail the empirical analysis and results obtained, in terms of wage differentials and marriage rates observed in our data.

\subsubsection{Empirical results for beauty premium}

Using our sample (men aged 20-50) ${ }^{10}$ we estimate models that are similar to the ones in Case et al.(2009). The dependent variable is the log of monthly labour income and on the right-hand side we include measures of height and weight, together with our control variables. For height we estimate pooled OLS models because height is time-invariant and hence fixed effects models would not produce an estimate. In contrast, for weight we estimate both pooled OLS and fixed effects models. Robust standard errors, clustered on the individual, are estimated in each case.

Our results show a significant and robust positive height premium. On the other hand, the sign of the non-obesity premium depends on the specification of our model; nonetheless, in general it is found to be quite small in magnitude and not significant. Given the aforementioned shortcomings of weight as a proxy for attractiveness, as well as the well-documented ambiguous nature of empirical results pertaining to the link between BMI and wages, this is not really surprising.

The results are shown in Table 3 below:

TABLE 3 ABOUT HERE (please see at the end of paper)

Model 1 shows a clear and significant height premium. ${ }^{11}$ For weight we estimate three separate models. Model 2 finds that increasing weight significantly affects wages, and therefore suggests a weight premium. However,

\footnotetext{
${ }^{10}$ We also estimate the models with men aged $20-40$ and $20-60$ and we find similar results.

${ }^{11}$ Case et al. (2009) also find a positive height premium using the BHPS. The estimated
} 
once we use the augmented Model 3 which includes height as well as weight, the estimate on weight halves and becomes insignificant, while the height premium remains. Finally, Model 4 is estimated using fixed effects and in this case the impact of increases in weight is once again found not significant.

\subsubsection{Empirical results for marriage premium}

We estimate the marriage wage premium for our different groups controlling for unobservable heterogeneity. The theoretical model assumes that productivity is homogenous, but the data is almost certainly affected by productivity differences. In order to produce robust estimates as part of our falsification test it is vital that productivity differences are controlled for. We do this using two methods: first, we include education as a regressor and second, we use fixed effects estimation - a more robust approach.

The basic regression equation is:

$$
\ln \left(w_{i t}\right)=\beta M_{i t}+\gamma^{\prime} X_{i t}+\alpha_{i}+\varepsilon_{i t}
$$

In the above, the dependent variable $w$ is the log of monthly income, $X_{i t}$ is a matrix of controls, $\alpha_{i}$ captures the individual specific time-invariant heterogeneity (including productivity), $M_{i t}$ is an indicator of an individual's marital status and $\varepsilon_{i t}$ is the standard idiosyncratic error term. The coefficient of interest is $\beta$ as this provides the estimate of the marriage premium.

Estimating this regression using pooled OLS assumes that $\alpha_{i}$ is zero. As already mentioned, it may be possible to control for potential productivity effects by including measures of education in the matrix of controls $X_{i t}$. Since this may not completely eradicate the problem of unobservable heterogeneity, a more robust estimation is carried out, one that involves a within-individual transformation of the data, which in turn sweeps out the fixed effects. This is in fact the standard model for estimating marriage wage premia. ${ }^{12}$

coefficients reported in their paper are different to the ones in this paper because they (i) include fewer control variables than in our models, (ii) create an hourly wage variable, (iii) use fewer waves of data, and (iv) measure height in inches rather than meters.

${ }^{12}$ See Cornwell and Rupert (1995). 
Table 4 below presents the regression results.

TABLE 4 ABOUT HERE (please see at the end of paper)

First, we estimate the OLS model that includes education dummies as extra regressors. The pooled OLS results on height show that the estimated marriage premium is positive and larger for men classified as "tall" than for "not tall". On its own, ignoring the fact that the OLS does not account for unobserved heterogeneity, this result would contradict the predictions of our model.

To overcome the problem of unobservable heterogeneity, we use fixed effects and find that the relationship is in fact reversed. The estimate for the "not tall" (less than $1.70 \mathrm{~m}$ ) group is positive, large and significant, while the coefficient for the "tall" (above 1.70m) group is close to zero and insignificant.

These results on marriage wage differentials appear to satisfy Test 1 part (b) which pertains to the ranking of marriage premia. Together with the evidence of a positive height premium reported above, the other relevant test is Test 2, which is also satisfied.

When we relax the threshold to $1.75 \mathrm{~m}$ the estimated marriage premium for the "not tall" group remains positive and significant and is, as expected, lower. The corresponding estimate for the "tall" group is still close to zero and insignificant. As some men - previously categorised as "tall"- move into the "not tall" group, their effect is to decrease the marriage premium for this group.

What is the effect of weight on wages? Once again, the pooled OLS yields a larger (and significant) wage premium for the attractive ("not obese") group. As before, in order to address the shortcomings of OLS, we estimate a fixed effects regression. The estimate for the "obese" is large. ${ }^{13}$ In contrast, the estimate for the "not obese" is low in magnitude and insignificant. Again, on their own, these results on marriage wage premia appear to satisfy Test 1 part $(b)$. Coupled with the evidence of a zero beauty premium as reported above, they also pass Test 3 .

\footnotetext{
${ }^{13}$ Although insignificant, this is likely to be the result of the small sample size.
} 


\subsubsection{Empirical results for marriage rates}

In order to investigate the effects of employment status and wages on marriage, we use a number a model specifications. The results are summarised in Table 5 below.

TABLE 5 ABOUT HERE (please see at the end of paper)

The first four columns show the estimated average partial effects (APE) from a random effects Probit, modelling the probability of marriage as a function of employment.

The results show that being employed increases the probability of marriage for the whole sample, as well as for "talls" and "not talls", taken separately. The estimated effect is positive and significant for both types. This is also true for the weight sample. These results for both height and weight add support to the predictions in Corollary 2.

The right-hand side frame of Table 5 reports APE from random effects Probits, modelling the probability of marriage for individuals who are employed. The key explanatory variable of interest is the log of monthly income. Model 1 reports results using current wages, while model 2 uses lagged wages. For the height sample, the effect is positive and significant in all cases, and higher for the "not tall" men. This is in line with Corollary 2(ii). For the weight sample, wages seem to affect the probability of marriage for the "not obese" more than for the "obese". Although the actual ranking of these effects does not seem to fit entirely, their sign is once again in accordance with the predictions of Corollary 2(ii).

\subsubsection{Age Robustness Checks}

In order to investigate whether the above results are sensitive to the defined age-groups, we re-estimated the marriage premium for age-groups 20-60 and 20-40, with the findings reported in Table 6 below. ${ }^{14}$

\footnotetext{
${ }^{14}$ It was not possible to obtain estimates for the 20-40 year old "obese" groups because of the reduced sample size.
} 
TABLE 6 ABOUT HERE (please see at the end of paper)

These results confirm our earlier findings. Although there is some variation in the estimated marriage premium, the magnitude is always larger (and often significant) for the unattractive group. For the attractive group the estimates are close to zero and not significant. These estimates demonstrate that our earlier results are robust to changes in the age-groups.

As an additional robustness check we re-estimated both the beauty premium and the marriage wage premium using two different age samples for height: a younger sample (age 20-29) and an older sample (40-49). ${ }^{15}$ This is relevant because individuals in the older sample may well be different to the men in the younger sample in terms of some other, potentially important, characteristics. Mature men are probably more relevant to our model, as their position in the life cycle implies lower expectations concerning divorce and relatively more stable marriages. We find that the results (summarised in Table 7) are largely the same: there is a beauty premium for both age groups, although not necessarily significant. The marriage premium is present for the "not talls" in both samples and there is no marriage wage premium for the "talls".

TABLE 7 ABOUT HERE (please see at the end of paper)

\subsection{Discussion}

We first address the results for the height sample. In terms of marriage premium only, we have found that the marriage premium of short men is positive, while the marriage premium for tall men is zero. This passes Test 1. We have also found a positive beauty premium. Potentially, the pattern

\footnotetext{
${ }^{15}$ It was not possible to do this for weight, as the sample size is too small.
} 
of marriage premia could falsify the model according to Test 2 above. Nevertheless, it passes that test because the marriage premium of short men was found to be positive.

As further evidence in support of our theory, we have found that employment status does indeed affect marriage rates both for short and tall men. Given our results on marriage premia, these findings are all in line with the predictions of Corollary 2. We have also found that the effect of wages on marriage rates is positive for both types of men, and lower for tall men than for short men. Strictly speaking, again based on our findings on marriage premia, the effect of wages on marriage for tall men should not only be lower than that for short men, but should in fact be equal to zero.

Next, we address the weight sample. In terms of marriage wage premium only, the most complete model specification (fixed effects) shows a much larger marriage premium for the obese than for the non obese. These results therefore pass Test 1 . The marriage premium for obese is indeed quite large, and although not significant, this is likely to be the result of the small sample size.

We also find that employment status and wages affect the probability of marriage for the obese, which is line with Corollary 2 (recall that we have found a positive marriage premium for obese men). Similarly, employment status affects the probability of marriage of non-obese men, and this is also in line with Corollary 2. However, contrary to the theoretical predictions, wages appear to affect the probability of marriage for these men as well.

Our paper is the first to consider the theoretical link between the beauty premium and the marriage wage premium, so it would be informative to also briefly consider how our empirical results relate to alternative theories of these two premia, as well as the potential relation between the two. In particular, the existence of a positive beauty premium would be consistent with theories relating beauty to selection, whereby beauty and wages are correlated through unobservable productivity. Discrimination could be another explanation.

In the case of height, where we do find a positive beauty premium, this result - in isolation - could be seen as consistent with the alternative theories. In principle, the use of fixed effects estimation for the beauty premium should enable us to control for both productivity and discrimination assuming, not 
unreasonably, that they are both time invariant. However, height is also time invariant and therefore such a strategy is not open to us. We do control for education, which may proxy for productivity but it does not fully control for unobservable heterogeneity.

Since we cannot estimate fixed effects models using height, we consider instead the extent to which our results for marriage premium (obtained using fixed effects) would offer support to alternative explanations of the beauty premium. As there are no other theoretical models investigating the link between beauty premium and marriage premium, we are required to make some assumptions relating either productivity or discrimination to marriage. Our working assumptions are that individuals who are more productive or not discriminated against, are more attractive in the marriage market. We also assume that productivity and discrimination status are time-invariant. These are reasonable assumptions and they allow us to make predictions regarding the marriage wage premium when the beauty premium is due to productivity differences or discrimination.

With this in mind, we argue that our empirical results support the search theoretical approach, rather than the selection or discrimination based explanations.

To see this, note that using OLS we obtain a positive marriage premium (see Table 3). If productivity differences or discrimination based on looks played a role in these results, OLS would be contaminated by unobservable heterogeneity. This is because the OLS cannot control for time invariant productivity status and discrimination status.

Using a fixed effects model would sweep out the influence of productivity differences and/or discrimination. Consequently, there should be a zero marriage wage premium for any type of individual: there is no mechanism through which married individuals should earn more than unmarried individuals (controlling for other factors such as age). Since we observe a positive marriage premium for short individuals and no marriage premium for tall men, this pattern cannot be due to productivity heterogeneity or looks-based discrimination only. 


\section{Conclusion}

The present paper makes several contributions. First, we offer an explanation for the so-called beauty premium by showing that marriage market expectations and behaviour affect labour market decisions (and vice versa). Our results rely entirely on the frictional nature of the two markets and on the natural assumption that physical attraction is important for successful marriage partnership formation. With women being selective about whom they marry (both in terms of looks and wages), men might struggle to find wages that are high enough to be deemed acceptable by females. If physical attributes and socio-economic status are perceived as substitutes, this effect is stronger for less attractive males, and consequently their chosen reservation wage may be lower than that of their more attractive rivals. This leads to a gap between the average wages of the two types of men. We find that market equilibria characterised by the beauty premium are robust, and therefore conclude that neither male productivity heterogeneity nor labour market discrimination are necessary for the existence of such earnings differentials.

Second, we show that the behaviour which leads to the beauty premium as an equilibrium outcome can also give rise to another, empirically welldocumented wage gap: the male marriage premium. By presenting the full profile of potential search equilibria, we are able to establish the link between these two types of premia and characterise various possible configurations of male wage differentials. Again, in contrast with existing explanations (all based on productivity heterogeneity), we argue that the inter-dependence between frictional labour and marriage markets can in itself generate this marriage premium.

Third, the predicted patterns of beauty premium and marriage wage premium provide the basis for a strong falsification test of our theory, and also point towards relevant supporting evidence. Using height and weight as proxies for attractiveness, and by looking at the wages of single and married men, we carry out an empirical test and we are able to conclude that the data does not refute the validity of the model. It is worth noting that ours is in fact the first attempt to assess empirically the role of search frictions in explaining the two types of earnings premia.

The model can be extended in several ways. Bonilla and Kiraly (2016) revisit the question of marriage premium by considering the setup with homo- 
geneous men, and allowing for divorce. In turn, Bonilla, Kiraly and Wildman (2015) look at a version of the model with two-sided heterogeneity, with men who differ in productivity and women who are characterised by various levels of attractiveness. This permits a characterisation of marriage premia across male types, as well as an analysis of marriage class formation - a richer set of predictions which are then tested empirically, contributing further to our understanding of the impact of search frictions in inter-dependent markets.

Indeed, over and above the results obtained in the present paper, which focus on a few very specific labour and marriage market outcomes, what we would like to emphasise is the elegance and power of models with interlinked frictional markets. To that end, the current work should be considered primarily as an illustration of such models as applied to an area (beauty premium and marriage premium) where no other previous approach seemed to us completely satisfactory.

In particular, the decision problem we call constrained search is the key building block. It is this that captures the considerations and trade-offs which stem from the link between two frictional markets, and the non-monotonicity of the optimal strategy is crucial for our results. ${ }^{16}$ Given this, we hope that our detailed exposition of the constrained sequential job search problem, together with the insight it seems to offer into various labour and marriage market outcomes may stimulate further research and new applications.

\section{References}

[1] Averett, S., A. Sikora, and L.M. Argys, "For Better or Worse: Relationship Status and Body Mass Index," Economics and Human Biology 6(3) (2008), 330-349.

[2] Becker, G., A Treatise on the Family, 3rd edition (Cambridge, MA: Harvard University Press, 1991).

[3] Blackburn, M., and S. Korenman, "The Declining Marital-Status Earnings Differential," Journal of Population Economics 7 (1994), 249-270.

\footnotetext{
${ }^{16}$ Bonilla and Kiraly (2014) look at constrained fixed sample search and show that the optimal strategy is also non-monotonic.
} 
[4] Bonilla, R., and F. Kiraly, "Marriage Wage Premium in a Search Equilibrium," Labour Economics 24 (2013), 107-115.

[5] Bonilla, R., and F. Kiraly, "Constrained Price Search", Newcastle University Discussion Paper (2014).

[6] Bonilla, R., and F. Kiraly, "Divorce and Marriage Premium", Newcastle University Discussion Paper (2016).

[7] Bonilla, R., F. Kiraly, and J. Wildman, "Marriage Premium and Class", Newcastle University Discussion Paper (2015).

[8] Case, A., and C. Paxson, "Stature and Status: Height, Ability and Labor Market Outcomes," Journal of Political Economy 112(5) (2008), 499-532.

[9] Case, A., C. Paxson, and M. Islam, "Making Sense of the Labor Market Height Premium: Evidence from the British Household Panel Survey," Economics Letters 102(3) (2009), 174-176.

[10] Cawley, J., "The Impact of Obesity on Wages," Journal of Human Resources 39(2) (2004), 451-474.

[11] Chiappori, P-A., S. Oreffice, and C. Quintana-Domeque, "Fatter Attraction: Anthropometric and Socioeconomic Matching on the Marriage Market," Journal of Political Economy 120(4) (2012), 659-695.

[12] Choo, E., and A. Siow, "Who Marries Whom and Why," Journal of Political Economy 114(1) (2006), 172-201.

[13] Chun, H., and I. Lee, "Why Do Married Men Earn More: Productivity or Marriage Selection?" Economic Inquiry 39 (2001) 307-319.

[14] Coles, M.G., and M. Francesconi, "On the Emergence of Toyboys: the Timing of Marriage with Aging and Uncertain Careers," International Economic Review 52(3) (2011), 825-853.

[15] Coles, M.G., and M. Francesconi, "Equilibrium Search and the Impact of Equal Opportunities for Women," University of Essex Discussion Paper (2013). 
[16] Cornwell, C., and P. Rupert, "Marriage and Earnings," Economic Review, Federal Reserve Bank of Cleveland issue Q IV (1995), 10-20.

[17] Daniel, K., "The Marriage Premium," in M. Tomassi and K. Ierulli, ed., The New Economics of Human Behavior (Cambridge, UK: Cambridge University Press, 1995).

[18] Garcia, J., and C. Quintana-Domeque, "Obesity, Employment, and Wages in Europe," in K. Bolin and J. Cawley, ed., Advances in Health Economics and Health Services Research, vol. 17, The Economics of Obesity (Amsterdam: Elsevier, 2007).

[19] Grossbard-Shechtman, S.A., and S. Neuman, "Marriage and Work for Pay," in Grossbard-Shechtman, S.A., ed., Marriage and the Economy (Cambridge, UK: Cambridge University Press, 2003).

[20] Hamermesh, D., Beauty Pays: Why Attractive People Are More Successful (Princeton, NJ: Princeton University Press, 2011).

[21] Hamermesh, D., and J. Biddle, "Beauty and the Labor Market," American Economic Review 84(5) (1994), 1174-1194.

[22] Han, E., E. Norton, and S. Stearns, "Weight and Wages: Fat versus Lean Paychecks," Health Economics 18 (2009), 535-548.

[23] Herpin, N., "Love, Careers and Heights in France," Economics and Human Biology 3 (2005), 420-449.

[24] Hersch, J., and L.S. Stratton, "Household Specialization and the Male Marriage Wage Premium," Industrial and Labor Relations Review 54(1) (2000), 78-94.

[25] Kaplan, G. and G. Menzio, "Shopping Externalities and Self-fulfilling Employment Fluctuations," Journal of Political Economy 124(3) (2016), 771-825.

[26] Korenman, S., and D. Neumark, "Does Marriage Really Make Men More Productive?" Journal of Human Resources 26(2) (1991), 282-307.

[27] Loh, E. S., "Productivity Differences and the Marriage Wage Premium for White Males," Journal of Human Resources 31(3) (1996), 566-589. 
[28] Manfredini, M., M. Breschi, A. Fornasin, and C. Seguieri, "Height, Socioeconomic Status and Marriage in Italy Around 1900," Economics and Human Biology 11 (2013), 465-473.

[29] Morris, S., "Body Mass Index and Occupational Attainment," Journal of Health Economics 25(2) (2006), 347-364.

[30] Mortensen, D.T., "The Matching Process as a Noncooperative Bargaining Game," in J.J. McCall, ed., The Economics of Information and Uncertainty (Chicago: University of Chicago Press, 1982).

[31] Oreffice, S., and C. Quintana-Domeque, "Anthropometry and Socioeconomics Among Couples: Evidence in the United States," Economics and Human Biology 8(3) (2010), 373-384.

[32] Persico, N., A. Postlewaite and D. Silverman, "The Effect of Adolescent Experience on Labor Market Outcomes: the Case of Height," Journal of Political Economy 112(5) (2004), 1019-1053.

[33] Ponthieux, S., and D. Meurs, "Gender Inequality," in: Atkinson, A.B. and F. Bourgouignon (Eds.), Handbook of Income Distribution (Vol. 2A). North Holland, Amsterdam, 2014.

[34] Ponzo, M., and V. Scoppa, "Trading Height for Education in the Marriage Market," American Journal of Human Biology 27 (2015), 164-174.

[35] Rupert, P., and E. Wasmer, "Housing and the Labor Market: Time to Move and Aggregate Unemployment," Journal of Monetary Economics 59 (2012), 24-36.

[36] Sargent, J.D., and D.G. Blanchflower, "Obesity and Stature in Adolescence and Earnings in Young Adulthood: Analysis of a British Birth Cohort," Archives of Pediatrics and Adolescent Medicine 148 (1994), 681-687.

[37] Silventoinen, K., J. Kaprio, E. Lahelma, R.J. Viken, and R.J. Rose, "Assortative Mating by Body Height and BMI: Finnish Twins and Their Spouses," American Journal of Human Biology 15(5) (2003), 620-627.

[38] Weiss, Y., and R. Willis, "Match Quality, New Information, and Marital Dissolution," Journal of Labor Economics 15 (1997), 293-329. 


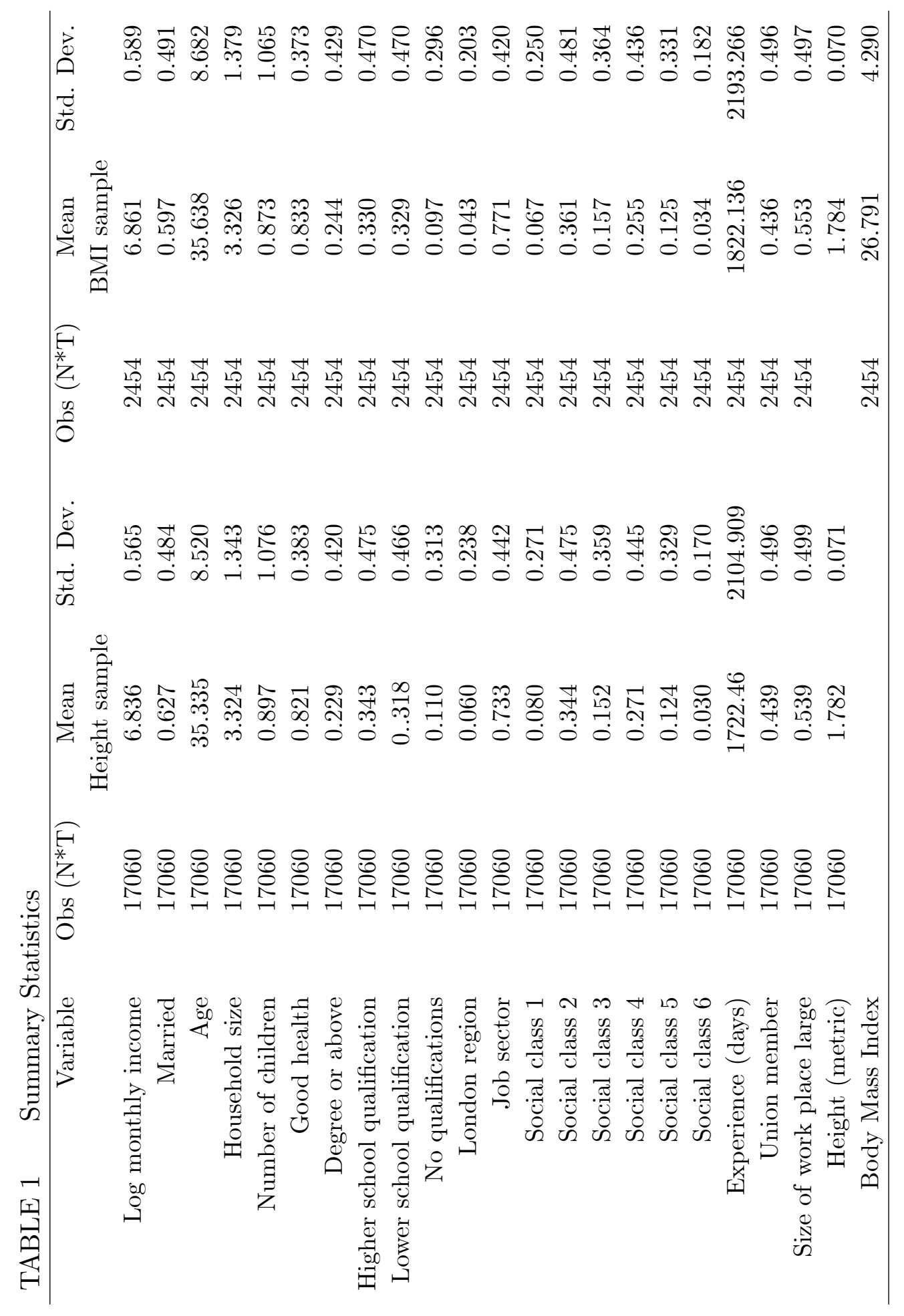


TABLE 2a Summary Statistics: Height

\begin{tabular}{lcccccc}
\hline & & Tall & & Not Tall \\
Variable & Obs & Mean & Std. Dev. & Obs & Mean & Std. Dev. \\
Log monthly income & 15465 & 6.847 & 0.560 & 1595 & 6.724 & 0.596 \\
Married & 15465 & 0.627 & 0.484 & 1595 & 0.629 & 0.483 \\
Age & 15465 & 35.269 & 8.513 & 1595 & 35.97 & 8.555 \\
Household size & 15465 & 3.324 & 1.341 & 1595 & 3.321 & 1.371 \\
Number of children & 15465 & 0.907 & 1.083 & 1595 & 0.797 & 1.002 \\
Good health & 15465 & 0.825 & 0.380 & 1595 & 0.782 & 0.413 \\
Degree or above & 15465 & 0.240 & 0.427 & 1595 & 0.124 & 0.330 \\
Higher school qualification & 15465 & 0.347 & 0.476 & 1595 & 0.310 & 0.463 \\
Lower school qualification & 15465 & 0.309 & 0.462 & 1595 & 0.405 & 0.491 \\
No qualifications & 15465 & 0.105 & 0.306 & 1595 & 0.161 & 0.368 \\
London region & 15465 & 0.060 & 0.238 & 1595 & 0.063 & 0.244 \\
Job sector & 15465 & 0.732 & 0.443 & 1595 & 0.739 & 0.439 \\
Social class 1 & 15465 & .082 & 0.274 & 1595 & 0.55 & 0.228 \\
Social class 2 & 15465 & 0.351 & 0.477 & 1595 & 0.267 & 0.443 \\
Social class 3 & 15465 & 0.158 & 0.365 & 1595 & 0.092 & 0.289 \\
Social class 4 & 15465 & 0.261 & 0.439 & 1595 & 0.369 & 0.483 \\
Social class 5 & 15465 & 0.119 & 0.324 & 1595 & 0.171 & 0.377 \\
Social class 6 & 15465 & 0.028 & 0.165 & 1595 & 0.046 & 0.209 \\
Experience (days) & 15465 & 1779.917 & 2105.814 & 1595 & 1914.082 & 2092.872 \\
Union member & 15465 & 0.437 & 0.496 & 1595 & 0.460 & 0.499 \\
Size of work place large & 15465 & 0.535 & 0.499 & 1595 & 0.577 & 0.494 \\
Height (metric) & 15465 & 1.795 & 0.060 & 1595 & 1.652 & 0.035 \\
\hline
\end{tabular}


TABLE 2b Summary Statistics: Obesity

\begin{tabular}{lcccccc}
\hline & \multicolumn{3}{c}{ Not Obese } & & Obese \\
Variable & Obs & Mean & Std. Dev. & Obs & Mean & Std. Dev. \\
Log monthly income & 1988 & 6.850 & 0.568 & 446 & 6.907 & 0.669 \\
Married & 1988 & 0.572 & 0.495 & 446 & 0.704 & 0.457 \\
Age & 1988 & 35.077 & 8.764 & 446 & 38.032 & 7.892 \\
Household size & 1988 & 3.285 & 1.409 & 446 & 3.500 & 1.229 \\
Number of children & 1988 & 0.846 & 1.074 & 446 & 0.987 & 1.020 \\
Good health & 1988 & 0.849 & 0.359 & 446 & 0.766 & 0.424 \\
Degree or above & 1988 & 0.246 & 0.431 & 446 & 0.232 & 0.422 \\
Higher school qualification & 1988 & 0.325 & 0.467 & 446 & 0.350 & 0.477 \\
Lower school qualification & 1988 & 0.335 & 0.472 & 446 & 0.305 & 0.461 \\
No qualifications & 1988 & 0.093 & 0.291 & 446 & 0.114 & 0.318 \\
London region & 1988 & 0.043 & 0.203 & 446 & 0.043 & 0.203 \\
Job sector & 1988 & 0.772 & 0.420 & 446 & 0.770 & 0.421 \\
Social class 1 & 1988 & 0.065 & 0.246 & 446 & 0.0773 & 0.267 \\
Social class 2 & 1988 & 0.366 & 0.482 & 446 & 0.343 & 0.475 \\
Social class 3 & 1988 & 0.160 & 0.367 & 446 & 0.146 & 0.353 \\
Social class 4 & 1988 & 0.251 & 0.434 & 446 & 0.270 & 0.445 \\
Social class 5 & 1988 & 0.121 & 0.326 & 446 & 0.142 & 0.349 \\
Social class 6 & 1988 & 0.037 & 0.189 & 446 & 0.021 & 0.145 \\
Experience (days) & 1988 & 1782.900 & 2157.076 & 446 & 1989.519 & 2336.423 \\
Union member & 1988 & 0.429 & 0.494 & 446 & 0.504 & 0.501 \\
Size of work place large & 1988 & 0.563 & 0.496 & 446 & 0.511 & 0.500 \\
Height (metric) & 1988 & 1.796 & 0.069 & 446 & 1.779 & 0.070 \\
Body Mass Index & 1988 & 25.22 & 2.493 & 446 & 33.493 & 3.869 \\
\hline
\end{tabular}


TABLE 3 Effect of Height and Weight on Wages

\begin{tabular}{lcclcc}
\hline $\begin{array}{l}\text { Height }(\mathrm{m}) \\
\text { Model 1 }\end{array}$ & OLS & 17,060 & Height $(\mathrm{m})$ & $0.404^{* * *}$ & $(0.109)$ \\
$\begin{array}{l}\text { Weight }(\mathrm{kg}) \\
\text { Model 2 }\end{array}$ & OLS & 2,425 & Weight $(\mathrm{kg})$ & $0.0013^{*}$ & $(0.0007)$ \\
Model 3 & OLS & 2,425 & Weight $(\mathrm{kg})$ & 0.0007 & $(0.0009)$ \\
& & & Height $(\mathrm{m})$ & $0.302^{*}$ & $(0.182)$ \\
Model 4 & Fixed Effects & 2,454 & Weight $(\mathrm{kg})$ & 0.001 & $(0.0012)$ \\
\hline
\end{tabular}

$*, * *, * * *: 10 \%, 5 \%$ and $1 \%$ level of significance

The dependent variable in all models is log monthly wages.

The models all show the estimates attached to the 'Married' variable. All models include a full range of controls: age, health, race, region, job sector, size of employer, occupational social class, experience, union membership, experience and year dummies. Clustered standard errors are presented in brackets.

Data on weight is only collected in waves 14 and 16 meaning that the sample sizes are lower. 
TABLE 4 Effect of Marital Status on Wages

\begin{tabular}{|c|c|c|c|c|c|}
\hline $\begin{array}{c}\text { Results } \\
\text { AGE 20-50 }\end{array}$ & & $\begin{array}{l}\text { Not tall } \\
(<1.70 \mathrm{~m})\end{array}$ & Tall & $\begin{array}{l}\text { Not tall } \\
(<1.75 \mathrm{~m})\end{array}$ & Tall \\
\hline OLS (including education) & Married & $\begin{array}{c}0.148^{* * *} \\
(0.055)\end{array}$ & $\begin{array}{c}0.190^{* * *} \\
(0.020)\end{array}$ & $\begin{array}{c}0.198^{* * *} \\
(0.033)\end{array}$ & $\begin{array}{c}0.181^{* * *} \\
(0.024)\end{array}$ \\
\hline Fixed Effects & Married & $\begin{array}{c}0.386^{* * *} \\
(0.111)\end{array}$ & $\begin{array}{l}-0.011 \\
(0.045)\end{array}$ & $\begin{array}{c}0.241^{* * *} \\
(0.071)\end{array}$ & $\begin{array}{c}-0.021 \\
(0.052)\end{array}$ \\
\hline $\mathrm{N}$ & & 1595 & 15465 & 4877 & 12183 \\
\hline OLS (including education) & Married & $\begin{array}{c}\text { Obese } \\
0.087 \\
(0.091)\end{array}$ & $\begin{array}{c}\text { Not obese } \\
0.173^{* * *} \\
(0.032)\end{array}$ & & \\
\hline Fixed Effects & Married & $\begin{array}{c}0.215 \\
(0.248)\end{array}$ & $\begin{array}{c}0.018 \\
(0.184)\end{array}$ & & \\
\hline $\mathrm{N}$ & & 466 & 1988 & & \\
\hline
\end{tabular}

The models all show the estimates attached to the 'Married' variable. All models include a full range of controls: age, health, race, region, job sector, size of employer, occupational social class, experience, union membership, experience and year dummies. The education dummies are degrees, higher school leaving qualifications (aged 18 A-levels or equivalents), lower school lever qualifications (aged 16 O-Level or equivalents) and no qualifications. Clustered standard errors are presented in brackets. Full results are available on request. 


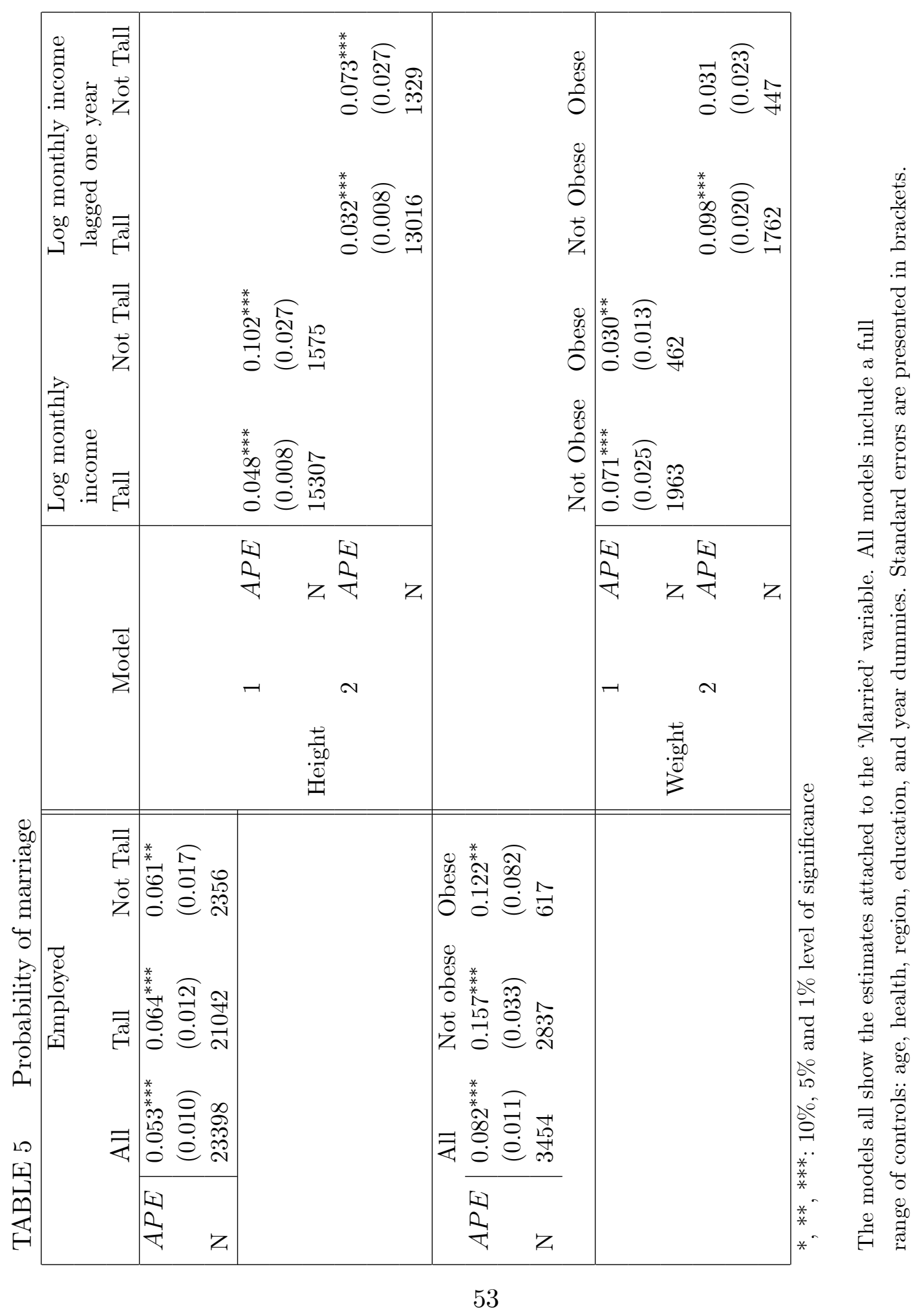


TABLE 6 Effect of Marital Status on Wages, by Age Groups

\begin{tabular}{|c|c|c|c|c|c|}
\hline $20-60$ & & Not tall & & Tall & \\
\hline $\mathrm{FE}$ & Married & $0.389^{* * *}$ & $(0.103)$ & 0.004 & $(0.041)$ \\
\hline $\mathrm{N}$ & & 2279 & & 19423 & \\
\hline & & Obese & & Not obese & \\
\hline $\mathrm{FE}$ & Married & 0.09 & $(0.151)$ & -0.01 & $(0.177)$ \\
\hline $\mathrm{N}$ & & 649 & & 2580 & \\
\hline $20-40$ & & Not tall & & Tall & \\
\hline $\mathrm{FE}$ & Married & $0.264^{* * *}$ & $(0.071)$ & -0.040 & $(0.047)$ \\
\hline $\mathrm{N}$ & & 960 & & 9824 & \\
\hline & & Obese & & Not obese & \\
\hline $\mathrm{FE}$ & Married & 1.276 & $(1.229)$ & $0.231^{* * *}$ & $(0.054)$ \\
\hline $\mathrm{N}$ & & 244 & & 1244 & \\
\hline
\end{tabular}

The models all show the estimates attached to the 'Married' variable. All models include a full range of controls: age, health, race, region, job sector, size of employer, occupational social class, experience, union membership, experience and year dummies. Clustered standard errors are presented in brackets. 
TABLE 7 Beauty Premium and Marriage Premium, by Age Groups

\begin{tabular}{|c|c|c|c|c|c|c|}
\hline & \multicolumn{2}{|c|}{ Beauty Premium } & \multicolumn{4}{|c|}{ Marriage Wage Premium } \\
\hline Age $20-29$ & & & Not & all & $\mathrm{Ta}$ & \\
\hline Height & 0.195 & $(0.121)$ & & & & \\
\hline Married & & & $0.345^{* * *}$ & $(0.163)$ & -0.012 & $(0.041)$ \\
\hline $\mathrm{N}$ & 4882 & & 415 & & 4467 & \\
\hline Age 40-49 & & & & & & \\
\hline Height & $0.654^{* * *}$ & $(0.184)$ & & & & \\
\hline Married & & & $0.298^{* * *}$ & $(0.112)$ & $-0.188^{* * *}$ & $(0.094)$ \\
\hline $\mathrm{N}$ & 6276 & & 635 & & 5641 & \\
\hline
\end{tabular}

$*, * *, * * *: 10 \%, 5 \%$ and $1 \%$ level of significance

The models all show the estimates attached to the 'Married' variable. All models include a full range of controls: age, health, race, region, job sector, size of employer, occupational social class, experience, union membership, experience and year dummies. Clustered standard errors are presented in brackets. 
APPENDIX $1 \quad$ Derivation of $\widetilde{T}_{i}$ used in the proof of Proposition 1.

If $J_{i}\left(\widetilde{T}_{i}\right)=V_{i}^{S}\left(w \mid w=\widetilde{T}_{i}\right)=\frac{\widetilde{T}_{i}}{r+\delta}+\frac{\lambda n}{(r+\delta)(r+\delta+\lambda n)} y$, then $\widetilde{T}_{i}$ is the reservation wage and it solves:

$$
\begin{gathered}
\frac{\widetilde{T}_{i}}{r+\delta}+\frac{\lambda n}{(r+\delta)(r+\delta+\lambda n)} y= \\
=\frac{\lambda_{0}}{r+\delta+\lambda_{0}} F\left(\widetilde{T}_{i}\right) \int_{\underline{w}}^{\widetilde{T}_{i}}\left[\frac{\widetilde{T}_{i}}{r+\delta}+\frac{\lambda n}{(r+\delta)(r+\delta+\lambda n)} y\right] d F\left(w^{\prime} \mid w^{\prime}<\widetilde{T}_{i}\right)+ \\
+\frac{\lambda_{0}}{r+\delta+\lambda_{0}}\left[1-F\left(\widetilde{T}_{i}\right)\right] \int_{\widetilde{T}_{i}}^{\bar{w}}\left[\frac{w}{r+\delta}+\frac{\lambda n}{(r+\delta)(r+\delta+\lambda n)} y\right] d F\left(w^{\prime} \mid w^{\prime}>\widetilde{T}_{i}\right) .
\end{gathered}
$$

The worker rejects any wage below $\widetilde{T}_{i}$ and stays on $J_{i}\left(\widetilde{T}_{i}\right)=V_{i}^{S}\left(\widetilde{T}_{i}\right)=$ $\frac{\widetilde{T}_{i}}{r+\delta}+\frac{\lambda n}{(r+\delta)(r+\delta+\lambda n)} y$. The worker accepts any wage offer above $\widetilde{T}_{i}$ and gets $\frac{w}{r+\delta}+\frac{\lambda n}{(r+\delta)(r+\delta+\lambda n)} y$. Note that, although the worker is marriageable when earning a wage $w \geq \widetilde{T}_{i}$, he is not marriageable while unemployed.

First, remove the conditionals in the distributions:

$$
\begin{gathered}
\frac{\widetilde{T}_{i}}{r+\delta}+\frac{\lambda n}{(r+\delta)(r+\delta+\lambda n)} y= \\
=\frac{\lambda_{0}}{r+\delta+\lambda_{0}} \int_{\underline{w}}^{\widetilde{T}_{i}}\left[\frac{\widetilde{T}_{i}}{r+\delta}+\frac{\lambda n}{(r+\delta)(r+\delta+\lambda n)} y\right] d F\left(w^{\prime}\right)+ \\
+\frac{\lambda_{0}}{r+\delta+\lambda_{0}} \int_{\widetilde{T}_{i}}^{\bar{w}}\left[\frac{w}{r+\delta}+\frac{\lambda n}{(r+\delta)(r+\delta+\lambda n)} y\right] d F\left(w^{\prime}\right) .
\end{gathered}
$$

Take $\frac{\lambda n}{(r+\delta)(r+\delta+\lambda n)} y$ out of the integrals on the right hand side and collect all terms to obtain:

$$
\frac{\widetilde{T}_{i}}{r+\delta}+\frac{\lambda n}{(r+\delta)(r+\delta+\lambda n)} y=
$$




$$
=\frac{\lambda_{0}}{r+\delta+\lambda_{0}}\left[\int_{\underline{w}}^{\widetilde{T}_{i}} \frac{\widetilde{T}_{i}}{r+\delta} d F\left(w^{\prime}\right)+\int_{\widetilde{T}_{i}}^{\bar{w}} \frac{w}{r+\delta} d F\left(w^{\prime}\right)+\frac{\lambda n}{(r+\delta)(r+\delta+\lambda n)} y\right] .
$$

Next, add and substract $\frac{\lambda_{0}}{r+\delta+\lambda_{0}} \int_{\widetilde{T}_{i}}^{\bar{w}} \frac{\widetilde{T}_{i}}{r+\delta} d F\left(w^{\prime}\right)$ to get:

$$
\frac{\widetilde{T}_{i}}{r+\delta}+\frac{\lambda n}{(r+\delta)(r+\delta+\lambda n)} y=\frac{\lambda_{0}}{r+\delta+\lambda_{0}}\left[\frac{\widetilde{T}_{i}}{r+\delta}+\int_{\widetilde{T}_{i}}^{\bar{w}^{w}} \frac{w-\widetilde{T}_{i}}{r+\delta} d F\left(w^{\prime}\right)+\frac{\lambda n}{(r+\delta)(r+\delta+\lambda n)} y\right] .
$$

Finally, the above simplifies to

$$
\widetilde{T}_{i}=\frac{\lambda_{0}}{r+\delta} \int_{\widetilde{T}_{i}}^{\bar{w}}\left[w-\widetilde{T}_{i}\right] d F\left(w^{\prime}\right)-\frac{\lambda n}{(r+\delta+\lambda n)} y<\underline{R} .
$$

APPENDIX 2 Derivation of $R_{i}$ in the proof of Remark 1.

As a reservation wage, $R_{i}$ solves $\frac{R_{i}}{r+\delta}=J_{i}$, so

$$
\begin{gathered}
\frac{R_{i}}{r+\delta}=\frac{\lambda_{0}}{r+\delta+\lambda_{0}} F\left(R_{i}\right) \int_{\underline{w}}^{R_{i}} \frac{R_{i}}{r+\delta} d\left[\frac{F(w)}{F\left(R_{i}\right)}\right]+ \\
+\frac{\lambda_{0}}{r+\delta+\lambda_{0}}\left[F\left(T_{i}\right)-F\left(R_{i}\right)\right] \int_{R_{i}}^{T_{i}} \frac{w}{r+\delta} d\left[\frac{F(w)}{F\left(T_{i}\right)-F\left(R_{i}\right)}\right]+ \\
+\frac{\lambda_{0}}{r+\delta+\lambda_{0}}\left[1-F\left(T_{i}\right)\right] \int_{T_{i}}^{\bar{w}}\left[\frac{w}{r+\delta}+\frac{\lambda n}{(r+\delta)(r+\delta+\lambda n)} y\right] d\left[\frac{F(w)}{1-F\left(T_{i}\right)}\right] .
\end{gathered}
$$


First, bring $\frac{\lambda n}{(r+\delta)(r+\delta+\lambda n)} y$ out of the integral and make use of

$$
\begin{gathered}
{\left[F\left(T_{i}\right)-F\left(R_{i}\right)\right] \int_{R_{i}}^{T_{i}} \frac{w}{r+\delta} d\left[\frac{F(w)}{F\left(T_{i}\right)-F\left(R_{i}\right)}\right]+\left[1-F\left(T_{i}\right)\right] \int_{T_{i}}^{\bar{w}} \frac{w}{r+\delta} d\left[\frac{F(w)}{1-F\left(T_{i}\right)}\right]=} \\
=\int_{R_{i}}^{\bar{w}} \frac{w}{r+\delta} d F(w)
\end{gathered}
$$

to obtain

$$
\begin{gathered}
\frac{R_{i}}{r+\delta}=\frac{\lambda_{0}}{r+\delta+\lambda_{0}} \int_{\underline{w}}^{R_{i}} \frac{R_{i}}{r+\delta} d F(w)+ \\
+\frac{\lambda_{0}}{r+\delta+\lambda_{0}}\left[\int_{R_{i}}^{\bar{w}} \frac{w}{r+\delta} d F(w)+\frac{\left[1-F\left(T_{i}\right)\right] \lambda n}{(r+\delta)(r+\delta+\lambda n)} y\right] .
\end{gathered}
$$

Next, add and substract $\int_{R_{i}}^{\bar{w}} \frac{R_{i}}{r+\delta} d F(w)$ to get

$$
\frac{R_{i}}{r+\delta}=\frac{\lambda_{0}}{r+\delta+\lambda_{0}}\left[\frac{R_{i}}{r+\delta}+\int_{R_{i}}^{\bar{w}} \frac{w-R_{i}}{r+\delta} d F(w)+\frac{\left[1-F\left(T_{i}\right)\right] \lambda n}{(r+\delta)(r+\delta+\lambda n)} y\right]
$$

Simplification and integration by parts lead to the $R_{i}$ from Remark 1 . 



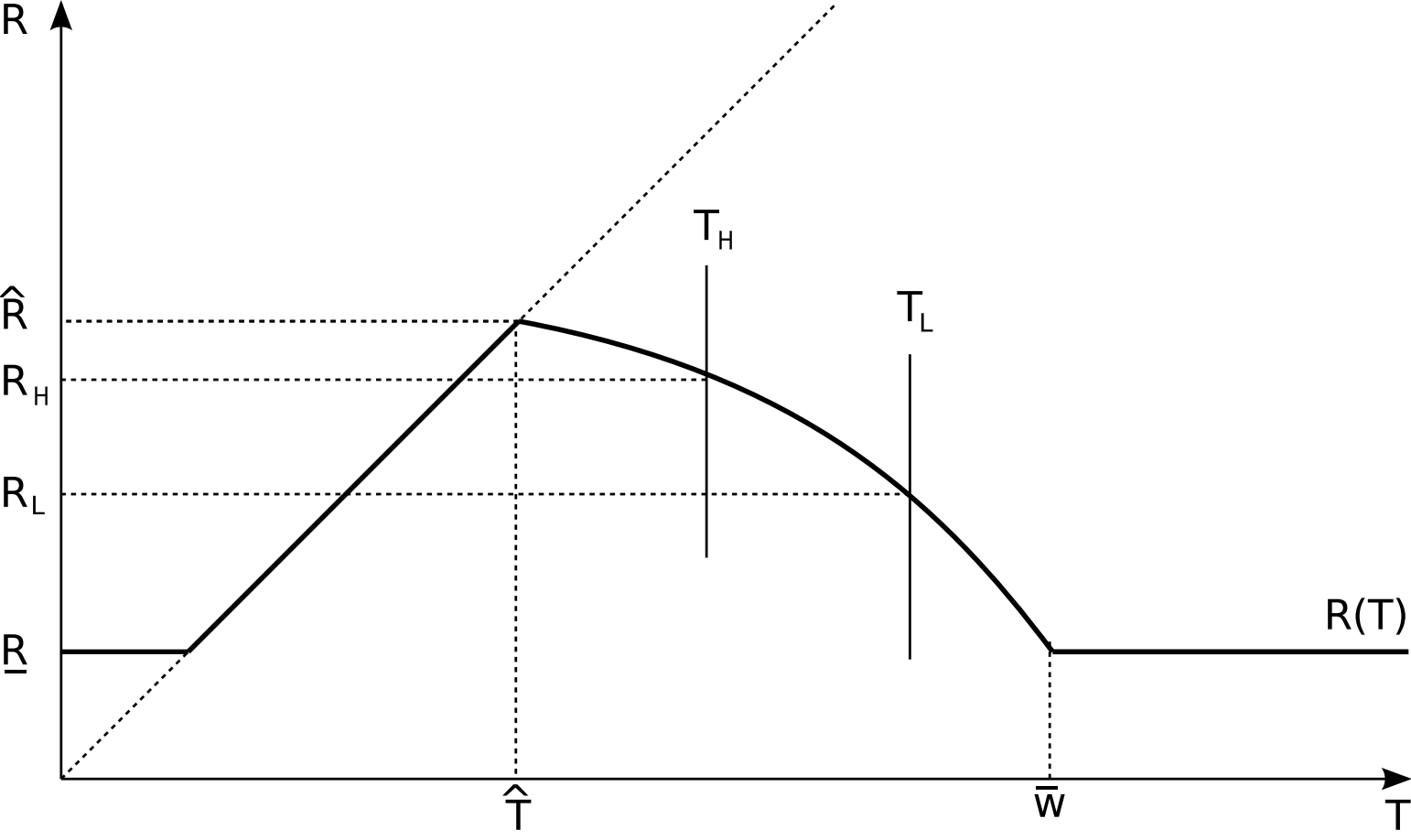

Figure 2 